CIRJE-F-1059

\title{
Demographics, Immigration, and Market Size
}

\author{
Koichi Fukumura \\ JSPS Research Fellow, Osaka University \\ Kohei Nagamachi \\ Kagawa University \\ Yasuhiro Sato \\ The University of Tokyo \\ Kazuhiro Yamamoto \\ Osaka University
}

July 2017

CIRJE Discussion Papers can be downloaded without charge from:

http://www.cirje.e.u-tokyo.ac.jp/research/03research02dp.html

Discussion Papers are a series of manuscripts in their draft form. They are not intended for circulation or distribution except as indicated by the author. For that reason Discussion Papers may not be reproduced or distributed without the written consent of the author. 


\title{
Demographics, immigration, and market size*
}

\author{
Koichi Fukumura $^{\dagger} \quad$ Kohei Nagamachi ${ }^{\ddagger} \quad$ Yasuhiro Sato $^{\S} \quad$ Kazuhiro Yamamoto
}

July 27,2017

\begin{abstract}
This paper constructs an overlapping generations model wherein people decide their number of children and levels of consumption for differentiated goods. We further assume that immigration takes place according to the utility difference between inside and outside a country. We show that an improvement in longevity has three effects on the market size and welfare: First, it decreases the number of children. Second, it increases the per capita expenditure on consumption. Finally, it increases immigration. The first effect has negative impacts on the market size and welfare whereas the latter two effects have positive impacts. We then calibrate our model to match Japanese and U.S. data from 1955 to 2014 and find that the negative effects dominate the positive ones. Moreover, our counterfactual analyses show that accepting immigration in Japan can be useful in overcoming population and market shrinkage caused by an aging population.
\end{abstract}

Keywords: demographics, market size, immigration, overlapping generations model JEL Classification Numbers: F22, J11, R23

\footnotetext{
${ }^{*}$ This study was conducted as a part of the Project "Spatial Economic Analysis on Trade and Labor Market Interactions in the System of Cities" undertaken at the Research Institute of Economy, Trade and Industry (RIETI). This work was also supported by JSPS KAKENHI Grant Number 15H03348, 15H03344, 16H03615, and 17H02519. We thank Keita Shiba, Ken Tabata, Masaaki Toma, and participants at 56th Annual Meeting of Western Regional Science Association for their helpful comments.

${ }^{\dagger}$ JSPS Research Fellow, Osaka University, e-mail: u958467k@ecs.osaka-u.ac.jp

${ }^{\ddagger}$ Kagawa University, e-mail: kohei.nagamachi@gmail.com

$\S$ University of Tokyo,e-mail: ysato@e.u-tokyo.ac.jp

๑Osaka University, e-mail: yamamoto@econ.osaka-u.ac.jp
} 


\section{Introduction}

Changes in a country's population consist of natural changes, which are determined by fertility and mortality, and social changes, which are determined by immigration. For the former change, we have observed very similar trends in many countries during the past half century, that is, consecutive improvements in longevity and declines in fertility. For instance, the life expectancy of age 15 males from 1955 to 2014 has steadily increased from 53.09 to 65.81 years in Japan and from 54.8 to 62.1 years in the United States. ${ }^{1}$ And from 1960 to 2015, the total fertility rate has declined from 2.00 to 1.46 in Japan and from 3.65 to 1.84 in the United States. In contrast to such similar natural changes, we have observed distinct differences in the social changes, that is, immigration between these countries. The number of total cumulative net immigrants from 1955 to 2014 was about 1.2 million in Japan and 40.3 million in the United States. Because Japan had a population of 127 million and the United States had a population of 319 million in 2014, the population of the United States is 2.5 times that of Japan, whereas immigration to the United States is 33.5 times that to Japan, implying that the United States has absorbed immigrants much more intensively than Japan. Such a difference in social changes inevitably results in a difference in population growth, which has become visible in recent years. The average annual population growth rate from 1955 to 1989 was $0.93 \%$ in Japan and $1.12 \%$ in the United States, while the figures from 1990 to 2014 were $0.12 \%$ in Japan and $1.02 \%$ in the United States. ${ }^{2}$ What can we uncover from such similarity in the natural changes and such difference in the social changes?

This paper aims to investigate the linkages among life expectancy, fertility, immigration, and population, and to uncover the possible impacts of increases in longevity on social welfare through changes in population. For this purpose, we focus on the role of market size. The population undoubtedly affects a country's market size, which in turn, is known to be a major engine that attracts firm activities in a global economy (Fujita et al., 1999; Baldwin et al., 2003; Combes et al., 2008). Hence, if a change in demographics increases the market size, firm activities will subsequently rush into the country, resulting in a rise in the country's welfare. If a change decreases the market size, the opposite holds true and there is a decline in the country's welfare. This is not the end of the story. If immigration takes place in response to the change in demographics, then it will also affect the country's market size and welfare.

In this paper, we develop an overlapping generations model wherein people decide their number of children, i.e., fertility, and their consumption levels of differentiated goods. Differentiated goods are produced under monopolistic competition, implying that a larger market size induces more firms to enter the market and increases the variety of differentiated goods, which increases the people's utility. Moreover, we assume a small open country and immigration occurs when the utility becomes higher inside the country than outside the country.

By using this framework, we examine the effects of improvements in longevity on population size, market size, and welfare. Our theoretical analysis shows that improvements in longevity affect the market size through three effects: First, it decreases fertility because parents need to prepare for consumption in their old period. Second, it increases the per capita lifetime consumption. Finally, it increases immigration, since the improved longevity raises the individual utility. The first effect has

\footnotetext{
${ }^{1}$ The sources of data used in this section are as follows. We obtained life expectancy data from the Life Table (Ministry of Health, Labour and Welfare) for Japan and the National Vital Statistics System (CDC/National Center for Health Statistics) for the United States. The total population size comes from the Vital Statistics (Ministry of Health, Labour and Welfare) for Japan and the Annual Estimates of the Resident Population for Selected Age Groups by Sex (Population Division, U.S. Census Bureau) for the United States. The total fertility rate for both countries is taken from http://data.worldbank.org/indicator/SP.DYN.TFRT.IN? on April 18, 2017. The immigration data comes from the Statistical Survey on Legal Migrants (Ministry of Justice) for Japan and the 2014 Yearbook of immigration Statistics (Office of Immigration Statistics, Department of Homeland Security) for the United States.

${ }^{2}$ Very recently, the Japanese population had already started to decrease. The 2015 Population Census reported that the Japanese population had decreased by 0.96 million from 2010 to 2015.
} 
negative impacts on the market size and welfare whereas the latter two effects have positive impacts.

We then calibrate our model to match the Japanese and U.S. data from 1955 to 2014 and conduct counterfactual analyses. Our first counterfactual analysis examines the effects of improvements in longevity and shows that a higher value for the survival rate results in a smaller market size. This implies that the negative impacts of improvements in longevity dominate the positive ones both in Japan and the United States.

Our second counterfactual analysis considers the scenario wherein Japan is as open towards immigration as the United States and the United States is as closed towards immigration as Japan. We then show that under this scenario Japan would have experienced a much higher growth in population and market size whereas the United States would have experienced much lower growth. This result implies that the United States has enjoyed gains from immigration whereas Japan can overcome shrinkages in its market size caused by aging if it accepts more immigrants.

Here, we present the related literature. Many existing studies including Acemoglu and Johnson (2007), Lorentzen et al. (2008), and Cervellatti and Sunde (2011) provided empirical evidences that longer life expectancy reduces the fertility rate. Several studies have developed frameworks that can explain this stylized fact: Kalemli-Ozcan $(2002,2003)$ and Kalemli-Ozcan et al. (2000) investigated the impact of uncertainty about the number of surviving children on fertility and population growth, and showed that if parents are risk averse, they reduce the number of children as the child's survival rate improves. Ehrlich and Lui (1991), Soares (2005), and Bar and Leukhina (2010) presented models wherein longer life expectancy leads parents to invest more in their children's education and to have fewer children. Yakita (2001), Zhang and Zhang (2001ab) and Miyazawa (2006) extended the model of accidental bequest a la Abel (1985) by endogenizing fertility, and showed that longer life expectancy induces people to save more when they are young in preparation for consumption when they are old, which decreases the number of children. In this paper, we also employ the model of the accidental bequest with endogenous fertility and further extend it by incorporating immigration and the market size effect on welfare.

Our analysis is also related to the literature on the impact of immigration on the labor markets of host countries that includes Card (2001, 2009), Borjas (2003), Ottaviano and Peri (2012), and Ottaviano et al. (2013), among others. These studies empirically investigated the impact of immigration on wage and employment in the host countries. We examine the impact of immigration using a larger scale by focusing on the market size, and theoretically investigating the welfare impacts. In this sense, our analysis is more closely related to the literature on trade and geography models a la Fujita et al. (1999), Baldwin et al. (2003) and Combes et al. (2008). In a standard trade and geography model, mobile workers are attracted to countries that offer a large variety of goods. Such immigration enlarges the host countries' market size and induces the entry of firms, which increases the variety of goods and welfare there. We depart from trade and geography models by incorporating the overlapping generations structure, longevity, and fertility.

Demographics consist of both natural changes and social changes. The first strand of the related literature focused only on the former and the second strand focused only on the latter. Our analysis bridges a gap between the two strands by considering the interlinkages among life expectancy, fertility, immigration, and market size in order to examine the possible impacts of improvements in longevity on the social welfare.

The paper is structured as follows. Section 2 provides the baseline model. Section 3 characterizes equilibrium and Section 4 examines the effects of improvements in longevity on the market size and welfare. Section 5 conducts calibration analyses. Section 6 concludes the paper. 


\section{The model}

\subsection{Individuals}

Consider a discrete time overlapping generations model wherein an individual resides in a small open country and lives for three periods: childhood, young (working), and old (retirement) periods. During childhood, the individual does nothing. While young, she works to obtain a wage income, consumes goods, and has children. When old, her children grows up to become young individuals and she spends her savings on consumption. We employ the individual's utility function as follows:

$$
U_{t}=\ln c_{y t}+\phi \beta \ln c_{o t+1}+\gamma \ln n_{t} .
$$

where $c_{y t}$ is the young individual's consumption in period $t$, and $c_{o t+1}$ is the old individual's consumption in period $t+1$. The subscripts $y$ and $o$ represents that the individual is young and old, respectively. Following the literature of endogenous fertility models, such as Eckstein and Wolpin (1985), we assume that individuals obtain utility from having children and that the level of utility depends on the number of children, $n_{t} . \beta, \gamma$, and $\phi$ are positive constants: $\beta$ represents the discount factor satisfying that $0<\beta<1$, and $\phi$ is the survival rate of a young individual living into the old period and satisfies that $0<\phi<1$. In this paper, the value of $\phi$ represents the degree of a society's longevity, and a rise in $\phi$ implies an improvement in longevity. We focus on changes in this parameter to investigate the impacts of increases in longevity on market structure and welfare.

We assume that consumption goods are differentiated and produced under monopolistic competition a la Dixit and Stiglitz (1977). Letting $M_{j t}$ denote the consumption of differentiated goods, $j$ individual's consumption $(j=y, o), c_{j t}$, is given by

$$
c_{y t}=M_{y t}, \quad c_{o t+1}=M_{o t+1} .
$$

Moreover, $M_{j t}$ is nested by a CES function as

$$
M_{j t}=\left(\int_{0}^{m_{t}} x_{j t}(i)^{(\sigma-1) / \sigma} d i+\int_{0}^{m_{w}} x_{w j t}(i)^{(\sigma-1) / \sigma} d i\right)^{\sigma /(\sigma-1)},
$$

where $\sigma$ is the elasticity of substitution satisfying that $\sigma>1 . x(i)$ is the consumption level of a particular differentiated good $i$. Here, $m_{t}$ and $m_{w}$ represent the number of differentiated goods produced in the country and that of differentiated goods imported from abroad (the rest of the world), respectively. The subscript $w$ represents the variable is related to the imported goods. Because we assume the country is small open, the number of imported differentiated goods, $m_{w}$, is exogenous whereas the number of domestically produced goods, $m_{t}$, is endogenous. As is well known in the literature on trade and geography models, the existence of such differentiated goods results in the backward-linkage effect (Fujita et al, 1999), which means that a larger market size encourages a greater number of firms to enter the market. This increases the number of available differentiated goods, and makes it possible for an individual to enjoy higher utility for a given nominal income. ${ }^{3}$ This effect plays a key role in understanding the relationship between the market structure and demographics. ${ }^{4}$

We assume a global capital market, so the assumption of a small open country implies that the interest, $R_{t}$, in a country is fixed at the exogenous world interest: $R_{t}=R$. To abstract from the risk associated with uncertain lifespans, we follow Blanchard (1985) and Yaari (1965) in assuming a perfect annuities market, that is, all savings are intermediated through mutual funds. At the end of

\footnotetext{
${ }^{3}$ In a multi-country setting involving trade of differentiated goods, this causes the home market effect, under which a country with a larger market size hosts a more than proportionate share of firms and production activities.

${ }^{4}$ We ignore the population distribution within a country, which can potentially affect the degree of backward linkage through responses of households' location choices. If we fully incorporate the multiple regions and location choices of firms and households, our model would explode and become intractable.
} 
her young period, each individual deposits her savings with a mutual fund. The mutual fund invests these savings in the global capital market and guarantees a gross return of $\widehat{R}$ to the survivors entering the old period. If a fund earns a gross return $\widehat{R}$ on its investment, then perfect competition yields $\widehat{R}=R / \phi$ in equilibrium. Having this in mind, the budget constraints are given as

$$
\begin{aligned}
w_{t} & =\int_{0}^{m_{t}} p_{t}(i) x_{y t}(i) d i+\int_{0}^{m_{w}} \tau p_{w} x_{w y t}(i) d i+b n_{t}+s_{t}, \\
\frac{R}{\phi} s_{t} & =\int_{0}^{m_{t+1}} p_{t+1}(i) x_{o t+1}(i) d i+\int_{0}^{m_{w}} \tau p_{w} x_{w o t+1}(i) d i .
\end{aligned}
$$

We describe the price of differentiated good $i$ by $p(i)$. To simplify the notation, we assume that the prices of differentiated goods imported from abroad are the same, that is, $p_{w}(i)=\tau p_{w}, \forall i \in\left[0, m_{w}\right]$, where $p_{w}$ is the price of a foreign differentiated good sold in the country of production, which is given and constant, because of an assumption of a small open economy. In this paper, we assume the iceberg transport cost, that is, to consume one unit of a foreign good, $\tau$ units of the good must be transported, where $\tau>1 .^{5}$ Equation (4) represents the young individual's constraint, where $s_{t}$ and $w_{t}$ are savings and wage income, respectively, and $b$ is a positive constant representing the child rearing cost. A young individual inelastically supplies her labor endowments, which are normalized to one, spends her wage income on the consumption of differentiated goods, child rearing, and savings. Equation (5) describes the old individual's constraint, wherein she uses her savings for consumption. We treat labor in the country as the numéraire. This implies that the wage income of a young individual is equal to one: $w_{t}=1$.

Plugging (2) and (3) into (1), and maximizing it under (4) and (5), we obtain the following demand functions for the differentiated goods: ${ }^{6}$

$$
x_{y t}(i)=\frac{1}{(1+\gamma+\phi \beta) p_{t}(i)^{\sigma} P_{t}^{1-\sigma}}, \quad x_{o t+1}(i)=\frac{\beta R}{(1+\gamma+\phi \beta) p_{t+1}(i)^{\sigma} P_{t+1}^{1-\sigma}},
$$

where $P_{t}$ is the price index defined as

$$
P_{t}=\left(\int_{0}^{m_{t}} p_{t}(i)^{1-\sigma} d i+\int_{0}^{m_{w}} \tau^{1-\sigma} p_{w}^{1-\sigma}\right)^{1 /(1-\sigma)} .
$$

The number of children is given by

$$
n_{t}=\frac{\gamma}{b(1+\gamma+\phi \beta)}
$$

and the level of savings, $s_{t}$, is determined as

$$
s_{t}=\frac{\phi \beta}{1+\gamma+\phi \beta} .
$$

By using (3) and (6), the young and old individuals' consumption (2) becomes as follows:

$$
c_{y t}=\frac{1}{P_{t}(1+\gamma+\phi \beta)}, \quad c_{o t+1}=\frac{\beta R}{P_{t+1}(1+\gamma+\phi \beta)} .
$$

We can observe that $\partial c_{y t} / \partial \phi<0, \partial n_{t} / \partial \phi<0, \partial s_{t} / \partial \phi>0$ and $\partial c_{o t+1} / \partial \phi<0$. When the survival rate rises, an individual has an incentive to increase her savings for old period consumption by decreasing her young period consumption and number of children. Despite such incentive, the old period consumption also decreases with the survival rate because of reductions in the real interest rate in this economy, $R P_{t} / \phi P_{t+1}$. Moreover, as is standard in trade and geography models, consumption and utility depend on the price index, $P_{t}$, which, in turn, depends on the market size as will be shown later.

\footnotetext{
${ }^{5}$ As we see later, under the iceberg transport cost, $\tau$, a profit maximizing firm sets its export price as the domestic price multiplied by $\tau$.

${ }^{6} x_{w y t}(i)$ and $x_{w o t+1}(i)$ are obtained by replacing $p_{t}(i)$ and $p_{t+1}(i)$ with $\tau p_{w}$ in $(6)$, respectively.
} 


\section{$2.2 \quad$ Firms}

Now we move to a description of the production structure. The differentiated goods are produced under monopolistic competition. To produce a differentiated good, $f$ units of labor are required as fixed inputs, and producing one unit of a differentiated good requires $c$ units of labor as variable inputs. Hence, letting $L_{t}$ denote the number of young individuals in period $t$, the profit of a firm producing differentiated good $i$ in a country is given as ${ }^{7}$

$$
\pi_{t}(i)=\left(p_{t}(i)-c\right)\left(x_{o t}(i) \phi L_{t-1}+x_{y t}(i) L_{t}\right)+\left(p_{w t}(i)-\tau c\right)\left(x_{w o t}(i) \phi_{w} L_{w t-1}+x_{w y t}(i) L_{w t}\right)-f .
$$

The first term represents the profit from domestic sales whereas the second term describes the profit from foreign sales. Here, we assume that the foreign demand structure is similar to the domestic demand structure. ${ }^{8}$ The profit function can be written as

$$
\pi_{t}(i)=\left(p_{t}(i)-c\right) \frac{M S_{t}}{p_{t}(i)^{\sigma} P_{t}^{1-\sigma}}+\left(p_{w t}(i)-\tau c\right) \frac{M S_{w}}{p_{w t}(i)^{\sigma} P_{w}^{1-\sigma}}-f
$$

where $M S_{t}$ is the country's market size and defined as

$$
M S_{t}=\frac{\phi \beta R}{1+\gamma+\phi \beta} L_{t-1}+\frac{1}{1+\gamma+\phi \beta} L_{t} .
$$

We define

$$
P_{w}=\left(\int_{0}^{m_{t}} \tau^{1-\sigma} p_{t}(i)^{1-\sigma} d i+\int_{0}^{m_{w}} p_{w}^{1-\sigma}\right)^{1 /(1-\sigma)} .
$$

The market size represents the aggregate income spent on consumption. The foreign market size, $M S_{w}$, is defined in a similar way and we assume it is exogenous. A firm's profit maximization with respect to price, $p_{t}(i)$, yields

$$
p_{t}(i)=p \equiv \frac{\sigma c}{\sigma-1}, \quad p_{w t}(i)=\tau p .
$$

From this, we readily know that the price index (7) and firm's profit (11) become

$$
\begin{aligned}
P_{t} & =\left(m_{t} p^{1-\sigma}+\delta m_{w} p_{w}^{1-\sigma}\right)^{1 /(1-\sigma)} \\
\pi_{t} & =\left(\frac{1}{\sigma}\right)\left[\frac{M S_{t}}{m_{t}+\delta m_{w}\left(c_{w} / c\right)^{1-\sigma}}+\frac{\delta M S_{w}}{\delta m_{t}+m_{w}\left(c_{w} / c\right)^{1-\sigma}}\right]-f .
\end{aligned}
$$

where $\delta$ is defined as $\delta \equiv \tau^{1-\sigma} \in(0,1)$ and denotes the degree of trade freedom. $c_{w}$ is defined as $c_{w} \equiv(\sigma-1) p_{w} / \sigma$, which represents the foreign marginal cost of production. As is standard in trade and geography models, (13) and (14) imply that a larger number of firms decreases the price index and the firm's profit:

$$
\frac{\partial P_{t}}{\partial m_{t}}<0, \quad \frac{\partial \pi_{t}}{\partial m_{t}}<0 .
$$

We assume free entry and exit of firms. Hence, new firms enter until the profit is driven to zero. In equilibrium, the number of firms, $m_{t}$, is determined by the following free-entry condition:

$$
\frac{M S_{t}}{m_{t}+\delta m_{w}\left(c_{w} / c\right)^{1-\sigma}}+\frac{\delta M S_{w}}{\delta m_{t}+m_{w}\left(c_{w} / c\right)^{1-\sigma}}=f \sigma .
$$

\footnotetext{
${ }^{7}$ This implies that the number of surviving old individuals in period $t$ becomes as $\phi L_{t-1}$, and the number of children in period $t$ is given by $n_{t} L_{t}$, which is the number of young individuals in period $t+1$.

${ }^{8}$ Note here that the foreign wage rate is not necessarily equal to one. Labor productivity can differ between countries.
} 
We can solve it for the equilibrium number of firms:

$$
\begin{aligned}
m_{t}= & \frac{1}{2 f \delta \sigma}\left[\delta\left(M S_{t}+M S_{w}\right)-f k \sigma m_{w}\left(1+\delta^{2}\right)\right] \\
& +\frac{1}{2 f \delta \sigma} \sqrt{\left[\delta\left(M S_{t}+M S_{w}\right)-f k \sigma m_{w}\left(1+\delta^{2}\right)\right]^{2}+4 f k \delta \sigma m_{w}\left[M S_{t}+\delta\left(\delta M S_{w}-f k \sigma m_{w}\right)\right]} \\
= & \frac{1}{2 f \sigma}\left(M S_{t}+M S_{w}\right)-\frac{k m_{w}}{2 \delta}\left(1+\delta^{2}\right) \\
& +\sqrt{\left[\frac{1}{2 f \sigma}\left(M S_{t}+M S_{w}\right)-\frac{k m_{w}}{2 \delta}\left(1+\delta^{2}\right)\right]^{2}+\frac{k m_{w}}{f \sigma}\left(\frac{M S_{t}}{\delta}+\delta M S_{w}\right)-\left(k m_{w}\right)^{2}}
\end{aligned}
$$

where $k$ is the relative marginal cost and defined as $k \equiv\left(c_{w} / c\right)^{1-\sigma}$. We know from (17) that a growth in market size induces further firm entry: $\partial m_{t} / \partial M S_{t}>0$, which, combined with (15), yields

$$
\frac{\partial P_{t}}{\partial M S_{t}}<0
$$

\subsection{Demographic structure}

Given the demand and supply sides structures described so far, we obtain the level of an individual's (indirect) utility, $V_{t}$. We assume that if $V_{t}$ is sufficiently large to exceed the exogenous level of a foreign individual's utility, $V_{w}$, immigrants will enter the country, and if $V_{t}$ is smaller than $V_{w}$, some individuals in the country will emigrate. We assume that only young individuals will enter and exit the country and that such migration will take place at the beginning of each period. ${ }^{9}$ Let $\lambda_{t}$ denote the number of (young) immigrants. From (8), the law of motion of the youth population can be described as

$$
L_{t+1}=\frac{\gamma}{b(1+\gamma+\phi \beta)} L_{t}+\lambda_{t+1} .
$$

The first term represents the number of young individuals born in the country whereas the second term represents the number of young individuals immigrating (emigrating) from abroad (to the country). The total number of young individuals in the next period is the sum of these two numbers. In this paper, we focus on the steady-state, which requires that the population size does not change over time.

\section{Equilibrium}

We characterize the steady-state equilibrium. First, we pin down the relationship between the youth population size, $L_{t}$, and the number of immigrants, $\lambda_{t}$, which is given by (25). For this, we need to know the means of dependence of the individual's indirect utility, $V_{t}$, on $L_{t}$. Plugging (8) and (10) into (1), an individual's Indirect utility in the country, $V_{t}$, can be written as

$$
\begin{aligned}
V_{t} & =\ln \frac{1}{(1+\gamma+\phi \beta) P_{t}}+\phi \beta \ln \frac{\beta R}{(1+\gamma+\phi \beta) P_{t+1}}+\gamma \ln \frac{\gamma}{(1+\gamma+\phi \beta) b} \\
& =\Psi(\phi)-\ln P_{t}-\phi \beta \ln P_{t+1},
\end{aligned}
$$

where $\Psi(\phi)$ is defined as $\Psi(\phi) \equiv \gamma(\ln \gamma-\ln b)+\phi \beta \ln (\beta R)-(1+\gamma+\phi \beta) \ln (1+\gamma+\phi \beta)$. Equation (20) implies that it is sufficient to examine the level of the price index to know the level of indirect utility. Moreover, (13) and (17) show that the market size, via the number of firms, determines the

\footnotetext{
${ }^{9}$ We assume this for analytical tractability. Issues related to the timing of migration are beyond the scope of this paper.
} 
price index, and as shown in (18), a larger market size results in a lower price index. Hence, all we need to know is the market size in order to examine the level of indirect utility.

From (20), we obtain

$$
\left.V_{t}\right|_{\lambda_{t}=\lambda_{t+1}=0}=\Psi(\phi)-\left.\ln P_{t}\right|_{\lambda_{t}=0}-\left.\phi \beta \ln P_{t+1}\right|_{\lambda_{t+1}=0} .
$$

From (12) and (19), the market size of the country can be written as

$$
\begin{aligned}
M S_{t} & =\left(\frac{1}{1+\gamma+\phi \beta}+\frac{b \phi \beta R}{\gamma}\right)\left(L_{t}-\lambda_{t}\right)+\frac{1}{1+\gamma+\phi \beta} \lambda_{t}, \\
M S_{t+1} & =\frac{\phi \beta R}{1+\gamma+\phi \beta} L_{t}+\frac{1}{1+\gamma+\phi \beta}\left[\frac{\gamma}{b(1+\gamma+\phi \beta)} L_{t}+\lambda_{t+1}\right] .
\end{aligned}
$$

In the absence of migration $\left(\lambda_{t}=\lambda_{t+1}=0\right)$, the market size then becomes as

$$
\begin{aligned}
\left.M S_{t}\right|_{\lambda_{t}=0} & =\left(\frac{1}{1+\gamma+\phi \beta}+\frac{b \phi \beta R}{\gamma}\right) L_{t}, \\
\left.M S_{t+1}\right|_{\lambda_{t+1}=0} & =\left(\frac{1}{1+\gamma+\phi \beta}+\frac{b \phi \beta R}{\gamma}\right) \frac{\gamma}{b(1+\gamma+\phi \beta)} L_{t},
\end{aligned}
$$

which implies that a larger youth population results in a larger market size. This, combined with (18), leads to a lower price index:

$$
\begin{aligned}
\frac{\left.\partial P_{t}\right|_{\lambda_{t}=0}}{\partial L_{t}} & =\frac{\left.\partial P_{t}\right|_{\lambda_{t}=0}}{\left.\partial M S_{t}\right|_{\lambda_{t}=0}} \frac{\left.\partial M S_{t}\right|_{\lambda_{t}=0}}{\partial L_{t}}<0 \\
\frac{\left.\partial P_{t+1}\right|_{\lambda_{t+1}=0}}{\partial L_{t}} & =\frac{\left.\partial P_{t+1}\right|_{\lambda_{t+1}=0}}{\left.\partial M S_{t+1}\right|_{\lambda_{t+1}=0}} \frac{\left.\partial M S_{t+1}\right|_{\lambda_{t+1}=0}}{\partial L_{t}}<0 .
\end{aligned}
$$

From (21), we readily know that the indirect utility rises along with an increase in the young population size:

$$
\frac{\left.\partial V_{t}\right|_{\lambda_{t}=\lambda_{t+1}=0}}{\partial L_{t}}>0
$$

Hereafter, we make the following assumption: ${ }^{10}$

\section{Assumption 1}

$$
\left.\lim _{L_{t} \rightarrow 0} V_{t}\right|_{\lambda_{t}=\lambda_{t+1}=0}<V_{w}<\left.\lim _{L_{t} \rightarrow \infty} V_{t}\right|_{\lambda_{t}=\lambda_{t+1}=0}
$$

This assumption requires that the indirect utility without young population is lower than a foreign individual's utility, $V_{w}$, whereas the indirect utility with an infinitely large young population is greater than $V_{w}$. Under Assumption 1, (24) ensures that there exists a certain threshold value of the youth population size, $L_{t}$, that satisfies $\left.V_{t}\right|_{\lambda_{t}=\lambda_{t+1}=0}=V_{w}$. We define such $L_{t}$ as $\widehat{L}^{11}$

To derive equilibrium, we assume that $\lambda_{t}$ is determined as follows:

$$
\lambda_{t+1}=\left\{\begin{array}{ccc}
\varepsilon+\mu\left(L_{t}-\widehat{L}\right) & \text { if } & \left.V_{t}\right|_{\lambda_{t}=\lambda_{t+1}=0}>V_{w}, \\
0 & \text { if } & \left.V_{t}\right|_{\lambda_{t}=\lambda_{t+1}=0}=V_{w}, \\
-\varepsilon+\mu\left(L_{t}-\widehat{L}\right) & \text { if } & \left.V_{t}\right|_{\lambda_{t}=\lambda_{t+1}=0}<V_{w},
\end{array}\right.
$$

\footnotetext{
${ }^{10}$ This assumption can be written in parameters as $\Psi(\phi)-(1+\phi \beta) \ln p_{w}\left(\delta m_{w}\right)^{1 /(1-\sigma)}<V_{w}<\Psi(\phi)$.

${ }^{11}$ Note that $\widehat{L}$ is time-invariant.
} 
where $\varepsilon$ and $\mu$ are positive constants. ${ }^{12}$ This specification implies that if the utility in the absence of migration is higher in the country than abroad in period $t$ (i.e., $L_{t}>\widehat{L}$ ), a certain number of immigrants $\left(\varepsilon+\mu\left(L_{t}-\widehat{L}\right)\right.$ young individuals) enter the country in the next period, and if the opposite holds true (i.e., $\left.L_{t}<\widehat{L}\right)$, a certain number of emigrants $\left(\varepsilon-\mu\left(L_{t}-\widehat{L}\right)\right.$ young individuals) exit the country. The size of immigrant flows depends on the difference between the current population and the population that equalizes the domestic utility and foreign utility. We assume that a certain mass, $\varepsilon$, of immigrants will move irrespective of the degree of utility difference to ensure the existence of a steady-state with a positive population size.

Given the relationship between $L_{t}$ and $V_{t}$ in hand, the law of motion of the youth population (19) can be depicted as in Figure 1.

[Figure 1 around here: The law of motion of youth population]

From Figure 1, we can readily see that no stable steady-state equilibrium with positive population size exists if $\mu+\gamma /[b(1+\gamma+\phi \beta)] \geq 1$. And if this inequality holds true, even a small perturbation makes $L_{t}$ eventually converge to 0 or diverge to infinity, implying that the steady-state is unstable. Because our focus is on a stable steady-state, we assume that $\mu+\gamma /[b(1+\gamma+\phi \beta)]<1$, which requires the survival rate to be sufficiently high.

\section{Assumption 2}

$$
\mu+\frac{\gamma}{b(1+\gamma+\phi \beta)}<1
$$

Under this assumption, a possible steady-state equilibrium is associated with a population size of $L^{*}$ determined by (19) and $L_{t+1}=L_{t}$, which is given by,

$$
L^{*}=\frac{\varepsilon-\mu \widehat{L}}{1-\mu-\gamma /[b(1+\gamma+\phi \beta)]} .
$$

For this to be attained, we need to impose that $L^{*}>\widehat{L}$. Under Assumption 2, imposing this inequality is equivalent to impose the following assumption.

\section{Assumption 3}

$$
\varepsilon>\left[1-\frac{\gamma}{b(1+\gamma+\phi \beta)}\right] \widehat{L}
$$

In the remaining parts of the paper, we assume Assumptions 1 to 3 . In Figure 2, we depict $L^{*}$.

[Figure 2 around here: Steady-state equilibrium]

Proposition 1 Under Assumptions 1 to 3, the model has a unique steady-state equilibrium with positive population size, $L^{*}$.

\footnotetext{
${ }^{12}$ Strictly speaking, (25) is defined for $L_{t} \geq \varepsilon$. For $L_{t}<\varepsilon$, we define $\lambda_{t+1}=-L_{t}$. In this paper, we focus on a case with sufficiently large $L_{t}$ where only $(25)$ is relevant.
} 


\section{Effects of improvements in longevity}

Now we are ready to investigate the impacts of increases in longevity. From (26), we can see that

$$
\frac{\partial L^{*}}{\partial \phi}=I_{m m}-F_{e r}
$$

where $I_{m m}$ and $F_{e r}$ are defined as

$$
\begin{aligned}
I_{m m} & \equiv-\frac{\mu}{1-\mu-\gamma /[b(1+\gamma+\phi \beta)]} \frac{\partial \widehat{L}}{\partial \phi}>0, \\
F_{e r} & \equiv \frac{b \beta(\varepsilon-\mu \widehat{L}) \gamma /[b(1+\gamma+\phi \beta)]^{2}}{\{1-\mu-\gamma /[b(1+\gamma+\phi \beta)]\}^{2}}>0 .
\end{aligned}
$$

$I_{m m}$ represents the effect that improved longevity induces more immigrants. In fact, $\partial \widehat{L} / \partial \phi$ describes the responsiveness of immigration to improvements in longevity. $-F_{\text {er }}$ represents the effect that improved longevity decreases the number of children. Thus, our model includes two channels through which longevity affects population size.

From (12) and (26), the market size in the steady-state equilibrium is written as

$$
M S^{*}=\frac{1+\phi \beta R}{1+\gamma+\phi \beta} L^{*}
$$

Differentiating this with respect to $\phi$, we obtain

$$
\frac{\partial M S^{*}}{\partial \phi}=C_{o n}+\Gamma \frac{\partial L^{*}}{\partial \phi}
$$

where $C_{o n}$ and $\Gamma$ are defined as

$$
\begin{aligned}
C_{o n} & \equiv \frac{\beta[R(1+\gamma)-1]}{(1+\gamma+\phi \beta)^{2}} L^{*}, \\
\Gamma & \equiv \frac{1+\phi \beta R}{1+\gamma+\phi \beta} .
\end{aligned}
$$

$C_{\text {on }}$ captures the effect of changes in per capita expenditure on consumption whereas $\Gamma \partial L^{*} / \partial \phi$ represents the effect of population changes. From (27) and (28), we know that

$$
\frac{\partial M S^{*}}{\partial \phi}>0 \Leftrightarrow I_{m m}+\frac{C_{o n}}{\Gamma}>F_{e r} .
$$

Proposition 2 An increase in longevity increases the market size if and only if $I_{m m}+C_{o n} / \Gamma>F_{e r}$.

Furthermore, from (18), (21), (29), and Assumption 3, we obtain the following proposition:

Proposition 3 An increase in longevity increases the individual's utility if $I_{m m}+C_{o n} / \Gamma>F_{e r}$.

Thus, we know from Propositions 2 and 3 that the improved longevity has a positive immigration effect, a positive consumption effect, and a negative fertility effect, and can enlarge the market size and result in higher utility if and only if the positive effects dominate the negative one.

Thus far, we have examined the characteristics of steady-state equilibrium. However, in calibrating our model to match the real data, there is no guarantee that the economy is in a steady-state. To understand the calibration results from the theoretical viewpoint, we present a short discussion about 
the longevity effects on population and market size dynamics, starting with the effects on population dynamics. Combining (19) and (25), we obtain

$$
L_{t+1}=\left\{\begin{array}{lll}
\frac{\gamma}{b(1+\gamma+\phi \beta)} L_{t}+\varepsilon+\mu\left(L_{t}-\widehat{L}\right) & \text { if } & \left.V_{t}\right|_{\lambda_{t}=\lambda_{t+1}=0}>V_{w} \\
\frac{\gamma}{b(1+\gamma+\phi \beta)} L_{t} & \text { if } & \left.V_{t}\right|_{\lambda_{t}=\lambda_{t+1}=0}=V_{w} \\
\frac{\gamma}{b(1+\gamma+\phi \beta)} L_{t}-\varepsilon+\mu\left(L_{t}-\widehat{L}\right) & \text { if } & \left.V_{t}\right|_{\lambda_{t}=\lambda_{t+1}=0}<V_{w}
\end{array} .\right.
$$

Differentiating the equation with respect to $\phi$, we obtain

$$
\frac{\partial L_{t+1}}{\partial \phi}=\left\{\begin{array}{lll}
-\frac{\gamma \beta}{b(1+\gamma+\phi \beta)^{2}} L_{t}-\mu \frac{\partial \widehat{L}}{\partial \phi} & \text { if } & \left.V_{t}\right|_{\lambda_{t}=\lambda_{t+1}=0} \neq V_{w} \\
-\frac{\gamma \beta}{b(1+\gamma+\phi \beta)^{2}} L_{t} & \text { if }\left.\quad V_{t}\right|_{\lambda_{t}=\lambda_{t+1}=0}=V_{w}
\end{array} .\right.
$$

The first term on the right hand side, $-\gamma \beta L_{t} /\left[b(1+\gamma+\phi \beta)^{2}\right]$, implies the negative fertility effect on population. The second term, $-\mu \partial \widehat{L} / \partial \phi$, positively affects population if $\partial \widehat{L} / \partial \phi<0$, which holds true under Assumption 2 and the definition of $I_{m m}(>0)$.

Next, we consider the effects on market size dynamics. By differentiating $M S_{t+1}$ with respect to $\phi$, from (12), (19) and (25), we obtain

$$
\begin{aligned}
\frac{\partial M S_{t+1}}{\partial \phi} & =\frac{\beta R(1+\gamma)}{(1+\gamma+\phi \beta)^{2}} L_{t}-\frac{\beta}{(1+\gamma+\phi \beta)^{2}} L_{t+1}+\frac{1}{1+\gamma+\phi \beta} \frac{\partial L_{t+1}}{\partial \phi} \\
& =\left\{\begin{array}{lll}
\frac{\beta R(1+\gamma)}{(1+\gamma+\phi \beta)^{2}} L_{t}-\frac{\beta}{(1+\gamma+\phi \beta)^{2}} L_{t+1}-\frac{\gamma \beta}{b(1+\gamma+\phi \beta)^{3}} L_{t}-\frac{\mu}{1+\gamma+\phi \beta} \frac{\partial \widehat{L}}{\partial \phi} & \text { if }\left.V_{t}\right|_{\lambda_{t}=\lambda_{t+1}=0} \neq V_{w} \\
\frac{\beta R(1+\gamma)}{(1+\gamma+\phi \beta)^{2}} L_{t}-\frac{\beta}{(1+\gamma+\phi \beta)^{2}} L_{t+1}-\frac{\gamma \beta}{b(1+\gamma+\phi \beta)^{3}} L_{t} & \text { if }\left.V_{t}\right|_{\lambda_{t}=\lambda_{t+1}=0}=V_{w}
\end{array}\right.
\end{aligned}
$$

The first term on the right hand side represents the positive consumption effect. The second and third terms show the negative fertility effect. The last term describes the positive immigration effect. Thus, again, an increase in longevity influences the market size via the three channels.

\section{Calibration}

In this section, we calibrate the model to match the Japanese and U.S. data from 1955 to $2014 .^{13}$ Because we focus on demographics and market size, we calibrate the equations that determine population dynamics (19) and market-size dynamics (22). For this purpose, we extend our baseline model as follows. First, in our baseline model, all individuals live for two periods, young and old. In our calibration, we assume that each period consists of 35 years, and there is one cohort in each year. This implies that a total of 70 cohorts exist in the country. The number of members in a cohort in a period is an endogenous variable which is determined by the fertility rates in the previous period. We set the initial value of a cohort's population size by age from ages 15 to 84 in 1955 . That is, we use the population size of age 15 in 1955 as the initial value of a cohort's population size, and the population size of age 16 in 1955 as that of another cohort's population size, and so on. We assume that the individuals whose ages are from 15 to 49 belong to the young period, and the individuals whose ages are from 50 to 84 are in the old period. Then, the size of the youth population in 1955 is the sum of the population sizes from ages 15 to 49, and the size of the old population is the sum of the population sizes from ages 50 to 84 . Each year, a cohort gets one year older. The oldest cohort in the young period survives with a probability of $\phi$ and enters into the old period. The oldest cohort in the old period exits the economy the next year. We assume that all immigrants belong to the youngest cohort.

Second, because labor is treated as the sole production input in our baseline model, the market size in the baseline model does not match the actual market size (natural logarithm of nominal GDP),

\footnotetext{
${ }^{13}$ The matlab codes for calibration are available upon request.
} 
which includes the output produced by other production factors. To fill the gap between the model's and the actual market sizes, we linearly transform the model's market size as $a_{0}+a_{1} M S_{t}$, and choose $a_{0}$ and $a_{1}$ to minimize the mean squared error (MSE). In conducting minimization, we employ the Adaptive Mesh Refinement method (AMR). ${ }^{14}$

\section{$5.1 \quad$ Data}

In calibrating our model, we use data for population by age, number of immigrants, nominal GDP, life expectancy, and interest rates from 1955 to 2014 . Here, we summarize the sources of the Japanese and U.S. data.

\section{Japanese data}

Japanese population size (in million persons) is taken from the Vital Statistics (Ministry of Health, Labour and Welfare). In each year, the population size of cohorts in the young period and that in the old period are calculated as the sum of population sizes from ages 15 to 49 and that from ages 50 to 84. We assume that the population size for the age 14 represents the number of birth, which becomes the population size of the youngest cohort of the young period in the next year. Net immigration size (in million persons) comes from the Statistical Survey on Legal Migrants (Ministry of Justice). We calculate the number by subtracting the people departing Japan from the people entering Japan (including the Japanese). We use the nominal GDP (in billion yen) published in the Annual Report on National Accounts, Department of National Accounts, Economic and Social Research Institute, Cabinet Office. Life expectancy is from the Life table (Ministry of Health, Labour and Welfare). Total average life expectancy at age $15 A v$ is calculated as follows: $A v=w_{m} a_{m}+w_{f} a_{f}$ where $a_{i}(i=m, f)$ is the life expectancy at age15 of each sex and $w_{i}(i=m, f)$ is the sex ratio of the 15 years old population. Yearly average nominal interest rates (Basic Discount Rate and Basic Loan Rate) are available in the Bank of Japan database (accessed at https://www.stat-search.boj.or.jp/index on January 13, 2016).

\section{U.S. data}

The U.S. population size (in million persons) is taken from the Annual Estimates of the Resident Population for Selected Age Groups by Sex for the United States (Population Division, United States Census Bureau). Net immigration size (in million persons, and only including persons with lawful permanent resident status) is taken from the 2014 Yearbook of immigration Statistics (Office of Immigration Statistics, Department of Homeland Security). We ignore illegal immigrants in the United States due to data restriction. Nominal GDP (in billion U.S. dollars) comes from the Bureau of Economic Analysis, United States Department of Commerce database (accessed at http://www.bea.gov/iTable/iTable.cfm?ReqID=9 on January 13, 2016). Life expectancy available in National Vital Statistics System (CDC/National Center for Health Statistics). Total average life expectancy at age 15 is obtained from calculations using this data source. Yearly average nominal interest rates (Federal funds effective rate) are available in the Federal Reserve Bank database (accessed at https://fred.stlouisfed.org/series/FEDFUNDS on January 13, 2016).

\footnotetext{
${ }^{14} \mathrm{AMR}$ first divides the admissible intervals of relevant parameters to create meshes, and picks one point from each mesh. Then it calculates the MSE for each point to find the point that minimizes the MSE. Next, it divides the neighborhood of the point with the minimum MSE to create finer meshes, and again picks one point from each mesh. It repeats this process until the chosen points converge. See Berger and Oliger (1984).
} 


\subsection{Parameters and calibration method}

In order to calibrate (19) and (22), we need to determine $\beta, \gamma, \varepsilon, \phi, \mu, b$, and $R$. We follow Eckstein et al. (1999) and choose the discount factor between the young and old periods, $\beta=2 / 3$, and the costs of child rearing, $b=0.11 .^{15}$

The preference for children, $\gamma$, is set to minimize MSE between the model's number of children and the actual population size of the age 14 in each year. We again use AMR to minimize MSE and set $\gamma_{J P}=0.00487$ and $\gamma_{U S}=0.00524$, where the subscripts $J P$ and $U S$ describes that the parameters are associated with Japan and the United States, respectively.

Immigration parameters, $\varepsilon$ and $\mu$, are determined to minimize MSE between the model's net immigration size and the actual net immigration size by using AMR, resulting in $\varepsilon_{J P}=0.03569$, $\mu_{J P}=0.00112, \varepsilon_{U S}=0.19639$, and $\mu_{U S}=0.01002$. Thus, we know that both parameters, $\varepsilon$ and $\mu$ are much higher in the United States than in Japan, reflecting the fact that the United States has been more open towards immigrants than Japan.

We assume that parameters $\beta, b, \gamma, \varepsilon$, and $\mu$ are constant over time. In contrast, we assume parameters $\phi$ and $R$, and hence, $\widehat{L}$, can be different over time. We allow $\phi$ to take different values for different years because we focus on the effects of improvements in longevity, implying the need to consider consecutive increases in longevity during the last half century. We use different $R$ s for different years because we have observed drastic declines in the interest rate in recent years. Because $\widehat{L}$ depends on $\phi$ and $R$, we need to set $\widehat{L}$ for each year.

We can calculate a parameter of longevity, $\phi$, for each year to match the model's expected longevity with the average lifespan at age 15 . Because the model's expected longevity is given by $35 \times(1-$ $\phi)+70 \times \phi, \phi$ is determined by $A v=35 \times(1-\phi)+70 \times \phi$ if we denote the average lifespan at age 15 by $A v$. Rearranging this equation, we obtain $\phi=(A v-35) / 35$. Figure 3 represents the obtained values of $\phi$, from which we confirm that both Japan and the United States experienced improvements in longevity over the past half century.

[Figure 3 around here: Survival rate $\phi$ ]

We determine the interest, $R$, by using yearly average nominal interest rates.

Finally, $\widehat{L}$ is determined by $\left.V_{t}\right|_{\lambda_{t}=\lambda_{t+1}=0}=V_{w}$ for different values of $\phi$ and $R$. Unfortunately, we have no clue to fix the indirect utility outside of the country, $V_{w}$. Moreover, $\left.V_{t}\right|_{\lambda_{t}=\lambda_{t+1}=0}$ includes parameters not specified so far, and they are difficult to be pinned down. Hence, we employ a heuristic method. We assume that $V_{w}$ is constant over time. First, we linearly approximate $\left.V_{t}\right|_{\lambda_{t}=\lambda_{t+1}=0}$ as $\left.V_{t}\right|_{\lambda_{t}=\lambda_{t+1}=0}=K_{0}+K_{1} \phi+K_{2} L_{t}+K_{3} R$. Note here that $K_{0}$ represents all parts not related to $\phi, L_{t}$, and $R$, and $K_{0}$ is constant over time. Then, substituting $\left.V_{t}\right|_{\lambda_{t}=\lambda_{t+1}=0}=V_{w}$, we can write $K_{1} \phi+K_{2} \widehat{L}=V_{w}-K_{0}-K_{3} R$. We obtain $k_{1} \phi+k_{2} \widehat{L}=1$, where $k_{i} \equiv K_{i} /\left(V_{w}-K_{0}-K_{3} R\right)$. Since $R$ takes the same value as that for the world and $V_{w}$ also involves the term $K_{3} R, V_{w}-K_{0}-K_{3} R$ must be constant over time. We then obtain $k_{1}$ and $k_{2}$ as follows: We develop simultaneous equations $k_{1} \phi_{1950}+k_{2} L_{1950}=1$ and $k_{1} \phi_{1955}+k_{2} L_{1955}=1$ by using $\phi$ for 1950 and $1955, \phi_{1950}$ and $\phi_{1955}$, and by setting $\widehat{L}$ to the actual population size of the young cohort in 1950 and $1955, L_{1950}$ and $L_{1955}$. We choose 1950 and 1955 because their immigration size were smaller in these years than in all other years of calibration, and hence $L_{1950}$ and $L_{1955}$ are considered to be reasonable approximations of $\widehat{L}$. ${ }^{1617}$ Solving the two equations, we obtain $k_{1}$ and $k_{2}$. Then, for the years of calibration, we can obtain $\widehat{L}$ by $\left(1-k_{1} \phi\right) / k_{2}$ for each year. We summarize the determination of these parameters in Table 1 , and describe the results of our calibration in Figure 4.

\footnotetext{
${ }^{15}$ Because there are 35 years in each period, $\beta=2 / 3$ implies that the annual discount rate is approximately 0.0117 . This value is close to recent annual interest rates in Japan.

${ }^{16}$ The numbers are 0.000939 (1950) and $-0.006601(1955)$ in Japan and $0.24919(1950)$ and 0.23779 (1955) in the United States.

${ }^{17}$ Because Japanese data on population size by age are not available from 1951 to 1954, we use data for 1950 and 1955.
} 
[Table 1 around here: Parameter values]

[Figure 4 around here: Calibration results]

As we can see from Figure 4, our calibrated model exhibits a good match with the actual data. In particular, it can successfully replicate the trends observed in the actual data although it fails to capture the effects of temporary shocks such as baby booms.

The Japanese population has increased for several decades after the Second World War, but it started to decrease in recent years. In contrast, the U.S. population has increased monotonically during the past sixty years. Our theoretical analysis implies that such difference between two countries might arise for three reasons. First, if the preference for children is higher in the United States than in Japan, then the United States would have higher fertility and higher population growth. However, the obtained values of $\gamma$ are similar for both two countries, and hence, we can not employ this possibility. Second, differences in the survival rate, $\phi$, can be a source of differences in population growth because a higher survival rate induces an individual to increase her savings for old period consumption by decreasing her young period consumption and number of children. Because the obtained values of $\phi$ for Japan are higher than those for the United States, the differences in $\phi$ can possibly explain the lower population growth rate (and recent negative population growth rate) in Japan. Finally, differences in immigration size might be a source of differences in population growth. Because the United States has higher immigration parameters, $\varepsilon$ and $\mu$, than Japan, a larger immigration size might have supported the United States consecutive population growth. Thus, we can consider the differences in $\phi$ and/or those in $\varepsilon$ and $\mu$ as the causes of differences in population growth between the two countries. However, our analysis so far can not tell us about the degree of contribution from these factors. To uncover this information, we conduct several counterfactual analyses in the next subsection.

\subsection{Counterfactual analysis}

In this section, we study the quantitative effects of changing longevity and immigration on population and market sizes by counterfactual analyses. First, we examine the effects of improvements in longevity. For this purpose, we consider the following two counterfactual scenarios: (i) the survival rate, $\phi$, takes the initial value (i.e., the value in 1955) for all years, and (ii) $\phi$ takes the value in 2014 for all years. ${ }^{18}$ As we can see from Figure 3, the values of $\phi$ have risen in the two countries over the past sixty years. Hence, by scenarios (i) and (ii) we can examine what the population and market sizes would look like if we observed no improvements in longevity and if we experienced improvements in longevity at the beginning of the years under consideration, respectively. Figures 5 and 6 show the results of our counterfactual analyses.

[Figure 5 around here: Counterfactual analysis: low survival rate]

[Figure 6 around here: Counterfactual analysis: high survival rate]

Figure 5 represents the analysis under scenario (i). In both Japan (Figure 5-a) and the United States (Figure 5-b), setting $\phi$ at its initial, low level does not significantly change the total population (Figures 5-a-(3) and 5-b-(3)). However, setting a low $\phi$ drastically affects the population distribution by increasing the number of births (young population) (Figures 5-a-(1) and 5-b-(1)) and decreasing the old population (Figures 5-a-(5) and 5-b-(5)). In addition, immigration size is larger for a lower $\phi$ (Figures 5-a-(2) and 5-b-(2)). Thus, both the number of births and immigration size positively

\footnotetext{
${ }^{18}$ For parameters other than $\phi$, we use the same values as those specified in the previous section.
} 
affect the market size. This is because $\widehat{L}$ does not change over time due to a constant $\phi$. Hence, from (25), immigration size grows as the population grows. Moreover, the effects on the number of births are sufficiently large to dominate the negative effects on the per capita expenditure on consumption, which corresponds to the per capita GDP here (Figures 5-a-(6) and 5-b-(6)). In such a case, as shown in Proposition 2, the market size becomes larger when we use a lower $\phi$, which we confirm in Figures 5-a-(4) and 5-b-(4). ${ }^{19}$

Figure 6 describes the analysis under scenario (ii). If we set $\phi$ to its latest, high value and keep it constant over time, then we observe opposite changes to those observed under a low $\phi$, that is, the number of births decreases (Figures 6-a-(1) and 6-b-(1)), which leads to decreases in immigration size (Figures 6-a-(2) and 6-b-(2)) and per capita expenditure on consumption (Figures 6-a-(6) and 6-b-(6)) to decrease the market size (Figures 6-a-(4) and 6-b-(4)). Thus, we know that over the past sixty years, the negative effects of increases in the survival rate have dominated the positive ones, implying that improvements in longevity have decreased the market size in Japan and the United States.

Although improvements in longevity have negatively affected the market size in both countries, the magnitude is smaller in the United States than Japan. Compared to the baseline calibration, scenario (i) increases the market size by $9.64 \%$ for the United States and $22.10 \%$ for Japan. And scenario (ii) decreases the market size by $10.52 \%$ for the United States and $11.17 \%$ for Japan. Where do such differences come from? As we can see in Table 1, we obtained very different values for the immigration parameters between the two countries, and thus, inducing us to focus on them as the potential causes of the differences in magnitude. To grasp the importance of immigration in determining the market size, we conduct the following counterfactual analyses: what do the population and market sizes look like if Japan (resp. the United States) has the immigration parameters of the United States (resp. those of Japan)? In so doing, we replace $\varepsilon_{J P}$ and $\mu_{J P}$ with $\varepsilon_{U S}$ and $\mu_{U S}$ to rerun our simulations. Given that both parameters are higher in the United States than Japan, such an exercise uncovers the effects of making Japan as open towards immigration as the United States and those of making the United States as closed towards immigration as Japan.

The results of our counterfactual analyses are given in Figures $7 .^{20}$

[Figure 7 around here: Counterfactual analysis: openness towards immigration]

In Figure 7, Japan experiences increases in the number of birth, immigrants, total and young cohort population sizes, market size, and per capita expenditure on consumption if it becomes as open towards immigration as the United States, and the United States experiences decreases in them if it becomes as closed towards immigration as Japan. This implies that immigration affects not only the current population size but also the population size of the next generation and their expenditures, resulting in large impacts on the market size.

A few comments are in order. First, our results indicate that large immigration inflows into the United States were a significant engine of economic growth over the past half century. If the United States had been as closed towards immigration as Japan, its market size would have been much smaller than that observed today. Second, our results also imply that Japan could avoid shrinkages in population and market sizes caused by aging if it becomes more open towards immigration. Given that the Japanese population has already started to decrease, it would be worthwhile for Japan to consider accepting immigrants as a possible option for overcoming its population and market size declines.

\footnotetext{
${ }^{19}$ Note here that Proposition 2 deals with the steady-state whereas our numerical analyses do not because the total population grows over time.

${ }^{20}$ In Figure 7 , we replace both $\varepsilon$ and $\mu$ between the two countries. If we replace only $\varepsilon$ or only $\mu$, we obtain very similar results to those shown in Figure 7. By comparing the case wherein we replace only $\varepsilon$ to that wherein we replace $\mu$, we can see that the effects on the number of birth and the cohort population distribution are larger in the former than in the latter. These results are available upon request.
} 


\subsection{Robustness}

In this section, we conduct a few robustness checks. First, we change the child rearing cost parameter $b$ by utilizing the results of Eckstein et al (1999), who obtained money and time cost parameters for child rearing as 0.11 and 0.29 , respectively. Thus, we check the case that $b=0.29$, which represents the case where child rearing costs only consist of time costs. We also check the case of $b=0.11+0.29=0.4$. In addition, we check the case wherein $b$ is $0.06,0.17$, or 0.23 in order to adjust the relationship between length of periods and individual's income in Eckstein et al. (1999) to those in our paper. Under all different values of $b$, we obtain very similar calibration and counterfactual results to those obtained under $b=0.11$. Hence, we here show the case of $b=0.4$ as a representative case in Figure 8 .

[Figure 8 around here: Robustness check: case of $b=0.4$ ]

Table 2 shows the estimated $\gamma$ under different values of $b$. From the table, we can see that a higher $b$ increases the estimated $\gamma$ to sustain the number of births, which indicates that changes in $b$ are absorbed by changes in $\gamma$.

[Table 2 around here: Robustness check: estimated $\gamma$ under different values of $b$ ]

Second, we change the discount factor to $\beta=(1.03)^{-35}=0.3554$ to achieve $3 \%$ depreciation per year, following Eckstein et al (1999). Our calibration results are similar to those in the case of $\beta=2 / 3$. However, the counterfactual results look somewhat different from the the case of $\beta=2 / 3$ especially in the counterfactual that assumes a high survival rate. Figure 9 shows the counterfactual result of a high survival rate in the case of $\beta=0.3554$, which is comparable to Figure 6 . By comparing Figure 9 with Figure 6, we find that the number of birth and population are larger in Figure 9 than in Figure 6 . This is because a lower $\beta$ relatively increases the demand for children and decreases the demand for future consumption. Note also that the magnitude of the increases in births and population is larger in Japan than in the United States. This may reflect the difference in the main source of population dynamics between Japan and the United States. In Japan, population dynamics are mainly driven by births. Thus, the population dynamics of Japan are sensitive to $\phi$ that determines the number of births. In contrast, population dynamics in the United States are mainly driven by immigrants. Thus, the population dynamics of the United States are not sensitive to $\phi$.

[Figure 9 around here: Robustness check: changing parameter $\beta$ ]

\section{Concluding remarks}

This paper developed an overlapping generations model with endogenous fertility and immigration. Because we employ monopolistic competition wherein firms produce differentiated goods, population size and hence, market size matter for welfare in our framework. We then investigated the effects of improvements in longevity on population size, market size, and welfare. Our theoretical analysis showed that improvements in longevity affect the market size through three effects: First, it decreases the number of children because parents need to prepare for consumption in the old period. Second, it increases the per capita lifetime consumption. Finally, it increases the immigration size. The first effect has negative impacts on the market size whereas the latter two effects have positive impacts. We then calibrated our model using Japanese and U.S. data from 1955 to 2014 and conducted counterfactual analyses. Our first counterfactual analysis examined the effects of improvements in longevity and showed that a lower survival rate results in a larger market size. This implies that the negative impacts dominate the positive ones, and that the improvements in longevity can be a major source of shrinkage in market size. Our second counterfactual analysis considered the scenario wherein Japan 
is as open towards immigration as the United States and the United States is as closed towards immigration as Japan. Under this scenario, we showed that Japan experienced much higher growth in terms of population and market size whereas the United States experienced much lower growth, implying that the United States enjoyed gains from immigration and that Japan can overcome the shrinkage of its market size, which was caused by aging, if it accepts more immigrants.

One of the most important future extensions would be to incorporate human capital. On the one hand, human capital accumulation increases the market size by raising wages as shown by Prettner et al. (2013), Strulik et al. (2013), and Prettner and Strulik (2016). On the other hand, it lowers fertility by increasing the opportunity costs of having children, which make the market size shrink. Moreover, Cervellati and Sunde (2005) pointed out that human capital accumulation can potentially improve longevity. Hence, human capital accumulation might be significantly related to our analysis and hence would be worth incorporating.

\section{References}

[1] Abel, A. B., (1985) Precautionary saving and accidental bequest. American Economic Review 75, 777-791.

[2] Acemoglu, D., and Johnson, S. (2007) Disease and development: The effect of life expectancy on economic growth. Journal of Political Economy 115, 925-985.

[3] Bar, M., and Leukhina, O., (2010) Demographic transition and industrial revolution: A macroeconomic investigation. Review of Economic Dynamics 13, 424-251.

[4] Baldwin, R., Forsloid, R., Martin, P., Ottaviano, G.I.P., and Robert-Nicoud, F., (2003) Economic Geography and Public Policy, Princeton University Press.

[5] Berger, M.J. and J. Oliger (1984) Adaptive mesh refinement for hyperbolic partial differential equations. Journal of Computational Physics 53, 484-512.

[6] Blanchard, O.J. (1985) Debt, deficits and finite horizons. Journal of Political Economy 93, 223247.

[7] Borjas, G.J., (2003) The labor demand curve is downward sloping: reexamining the impact of immigration on the labor market. Quarterly Journal of Economics 118, 1335-1374.

[8] Card, D., (2001) Immigrant inflows, native outflows, and the local labor market impacts of higher immigration. Journal of Labor Economics 19, 22-64.

[9] Card, D. (2009) Immigration and inequality. American Economic Review 99, 1-21.

[10] Cervellati, M., and Sunde, U., (2005) Human capital, life expectancy, and the process of development. American Economic Review 95, 1653-1672.

[11] Combes, P.P., Mayer, T., and Thisse, J.F. (2008) Economic Geography: The Integration of Regions and Nations, Princeton University Press.

[12] Dixit, A.K., and J.E. Stiglitz (1977) Monopolistic competition and optimum product variety. American Economic Review 67, 297-308.

[13] Eckstein, Z., and K.I. Wolpin (1985) Endogenous fertility and optimal population size. Journal of Public Economics 27, 93-106. 
[14] Eckstein, Z., P.S. Mira, and K. Wolpin (1999) A quantitative analysis of Swedish fertility dynamics: 1751-1990. Review of Economic Dynamics 2, 137-165.

[15] Ehrlich, I., and Lui, F. T., (1991) Intergenerational trade, longevity, and economic growth. Journal of Political Economy 99, 1029-1059.

[16] Fujita, M., P. Krugman, and A.J. Venables (1999) The Spatial Economy, Cambridge, MA: MIT Press.

[17] Kalemli-Ozcanm S. (2002) Dose mortality decline promote economic growth? Journal of Economic Growth 7, 411-439.

[18] Kalemli-Ozcan S. (2003) A stochastic model of mortality, fertility, and human capital investment. Journal of Development Economics 70, 103-118.

[19] Kalemli-Ozcan S., Ryder, H. E., and Weil, D. N., (2000) Mortality decline, human capital investment, and economic growth. Journal of Development Economics 62, 1-23.

[20] Lorentzen, P., McMillan, J., and Wacziarg, R. (2008) Death and development. Journal of Economic Growth 13, 81-124.

[21] Miyazawa, K., (2006) Growth and inequality: a demographic explanation, Journal of Population Economics 19, 559-578.

[22] Ottaviano, G.I.P. and Peri, G., (2012) Rethinking the effect of immigration on wages. Journal of the European Economic Association 10, 152-197.

[23] Ottaviano, G.I.P., Peri, G., and Wright G.C., (2013) Immigration, offshoring, and American Job. American Economic Review 103, 1925-1959.

[24] Prettner, K., Bloom, D., and Strulik, H., (2013) Declining fertility and economic well-being: Do education and health ride to the rescue? Labor Economics 22, 70-79.

[25] Prettner, K, and Strulik, H., (2016) Technology, trade, and growth: The role of education. Macroeconomic Dynamics 20, 1381-1394.

[26] Soares, R., (2005) Mortality reductions, educational attainment, and fertility choice. American Economic Review 95, 580-601.

[27] Strulik, H., Prettner, K., and Prskawetz, A., (2013) The past and future of knowledge-based growth. Journal of Economic Growth 18, 411-437.

[28] Yaari, M. (1965) Uncertain lifetimes, life insurance, and the theory of the consumer. Review of Economic Studies 32, 137-150.

[29] Yakita, A. (2001) Uncertain lifetime, fertility and social security. Journal of Population Economics 14, 635-640.

[30] Zhang, J., and Zhang, J., (2001a) Longevity and economic growth in a dynastic family model with an annuity market. Economics Letters 72, 269-277.

[31] Zhang, J., and Zhang, J., (2001b) Bequest motives, social security, and economic growth. Economic Inquiry 39, 453-466. 


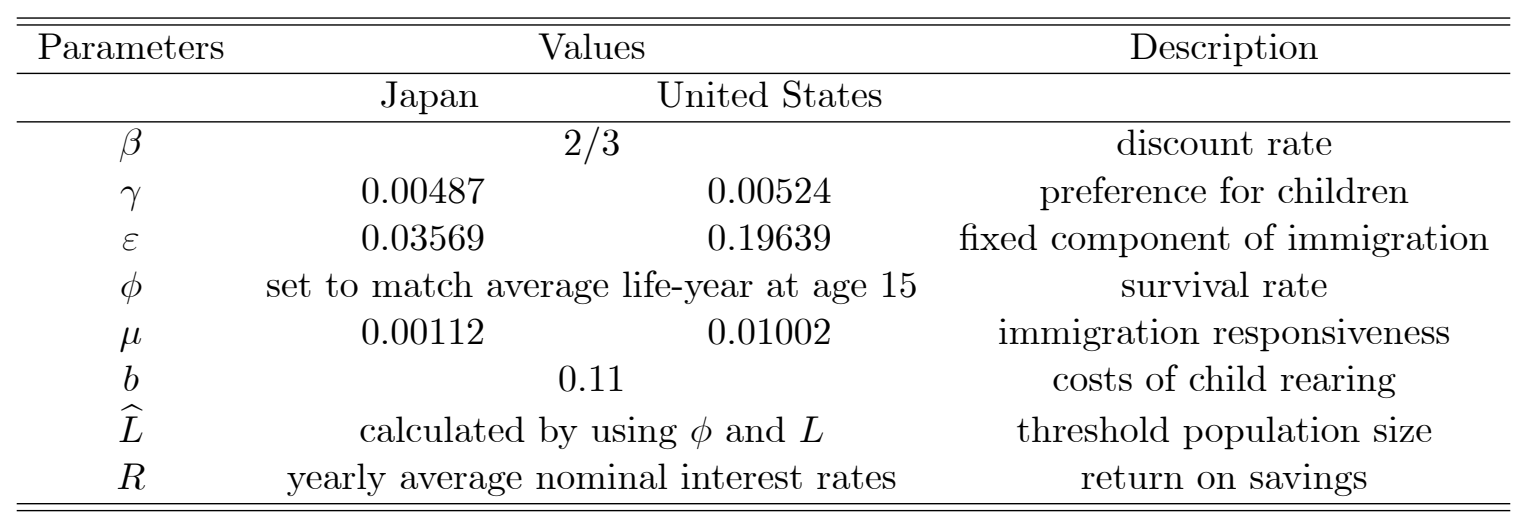

Table 1: Parameter values

\begin{tabular}{ccc}
\hline \hline$b$ & $\gamma_{J P}$ & $\gamma_{U S}$ \\
\hline 0.06 & 0.002651 & 0.002852 \\
0.11 & 0.004867 & 0.005237 \\
0.17 & 0.007535 & 0.008110 \\
0.23 & 0.010213 & 0.010993 \\
0.29 & 0.012900 & 0.013888 \\
0.40 & 0.017851 & 0.019224 \\
\hline \hline
\end{tabular}

Table 2: Robustness check: estimated $\gamma$ under different values of $b$ 


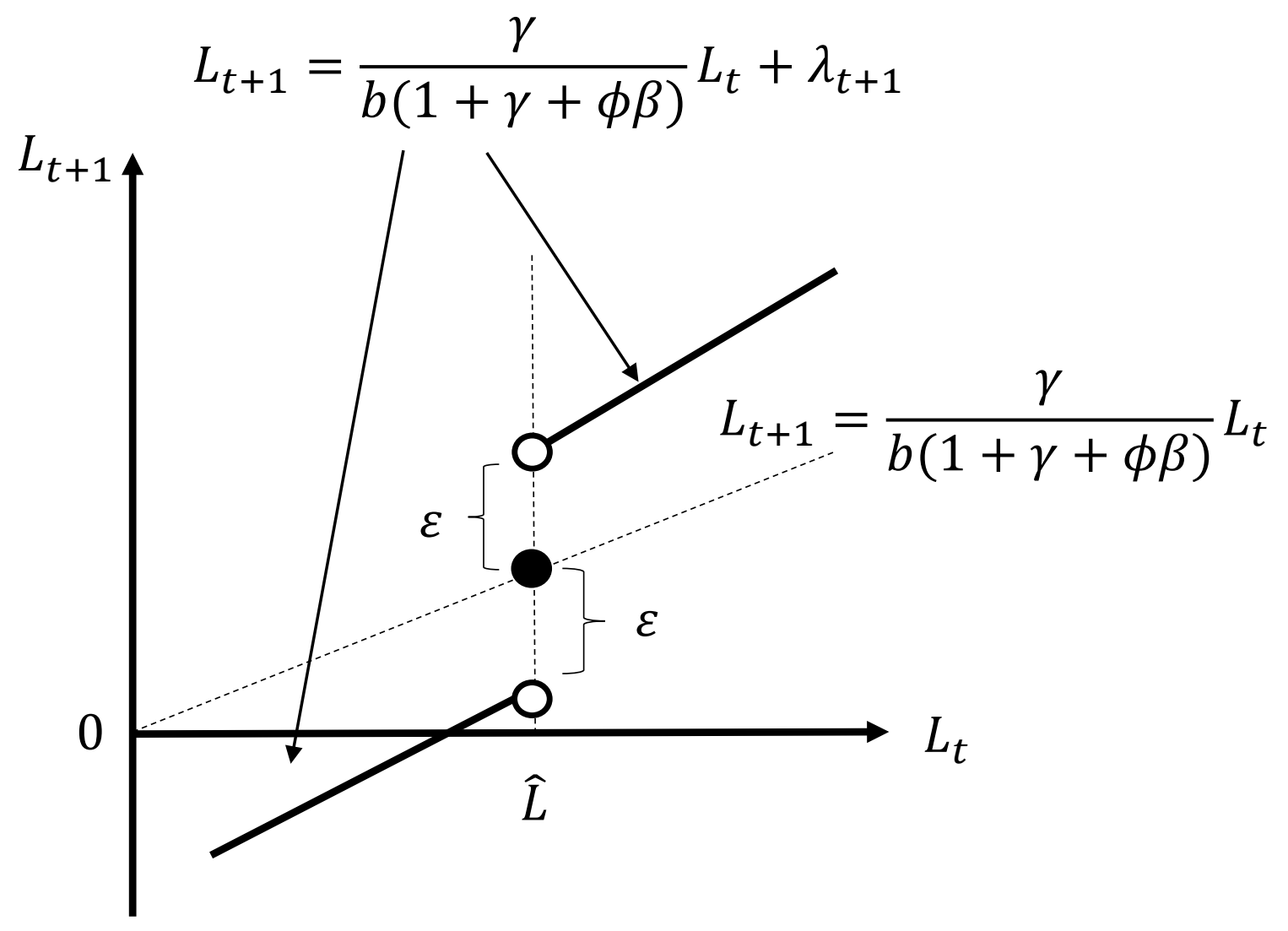

Figure 1. The law of motion of youth population 


$$
L_{t+1}=\frac{\gamma}{b(1+\gamma+\phi \beta)} L_{t}+\lambda_{t+1}
$$

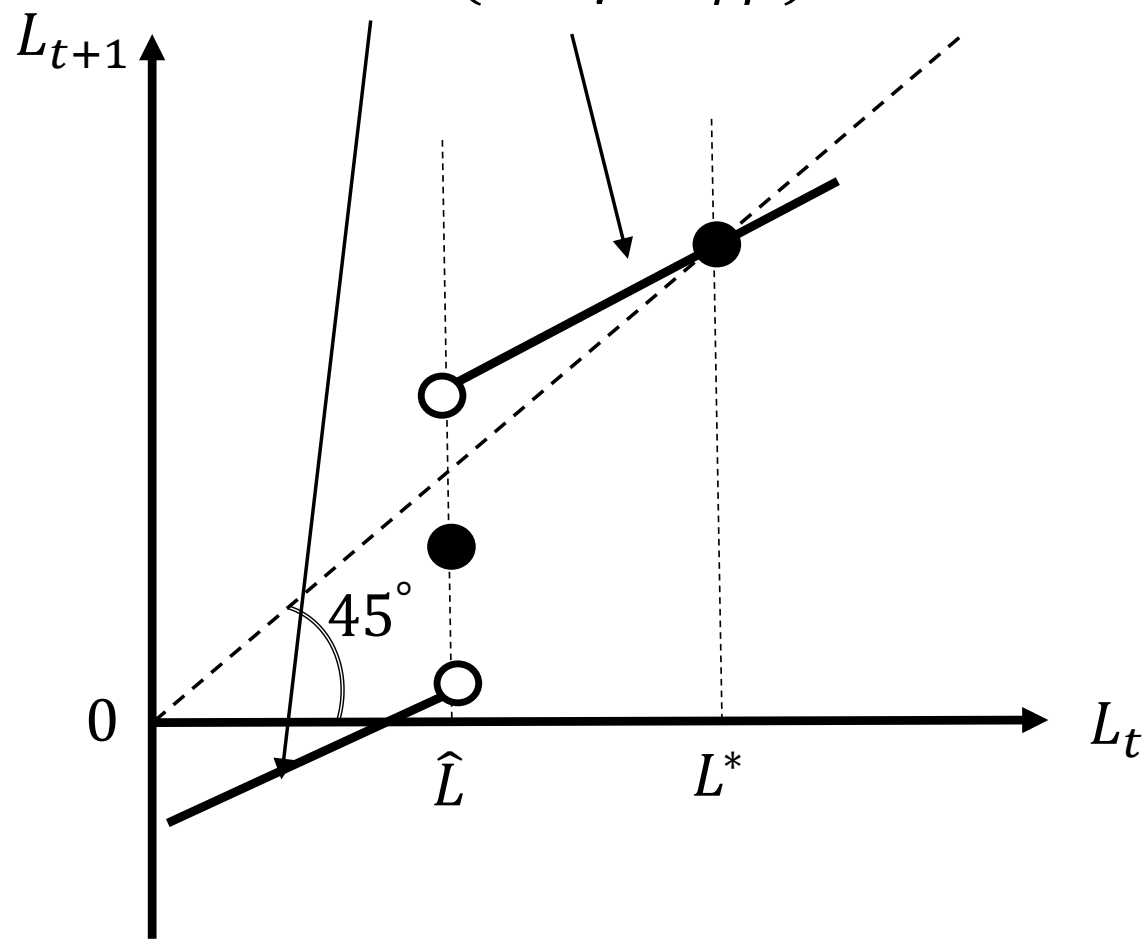

Figure 2. Steady-state equilibrium 


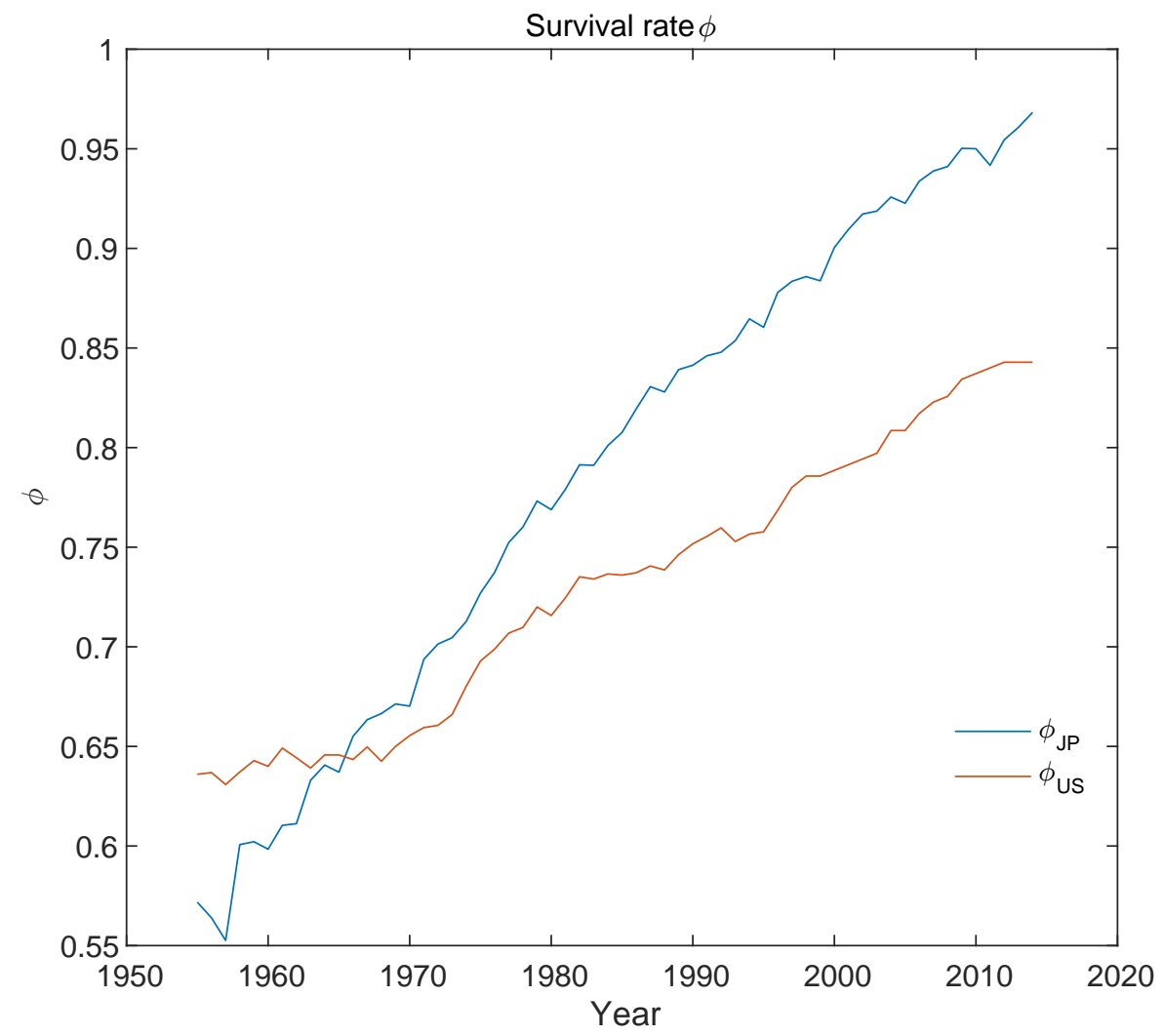

Figure 3: Survival rate $\phi$ 
(1) Number of Birth

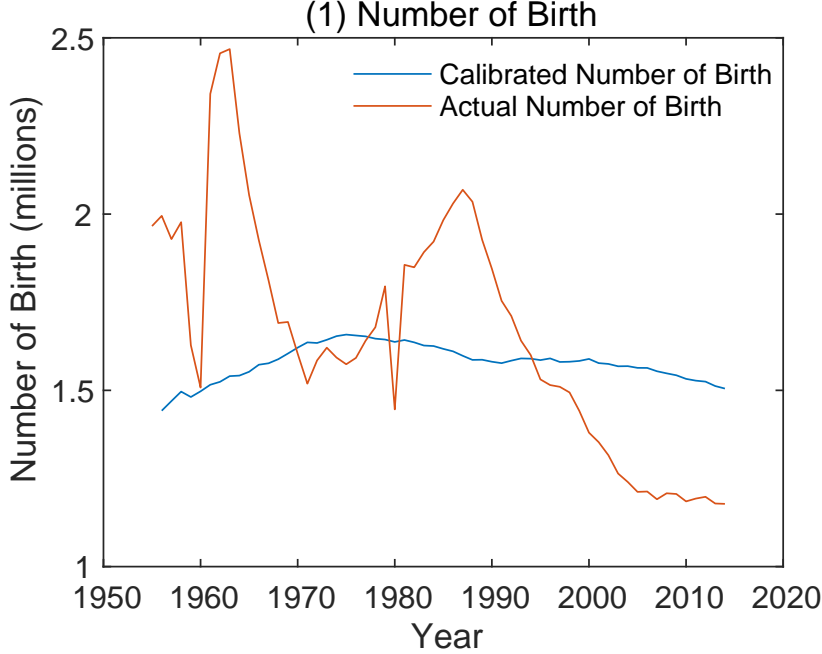

(3) Total Population

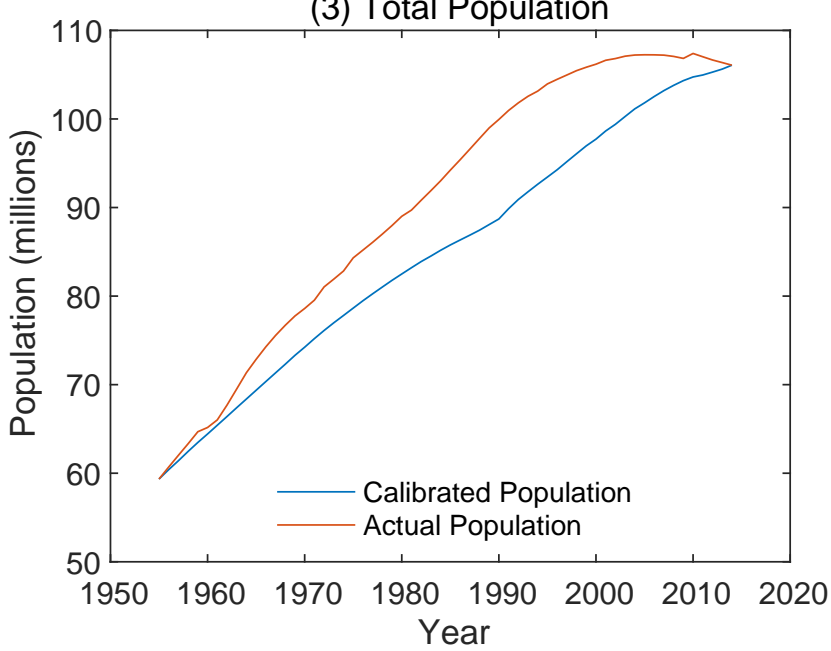

(5) Cohort Population

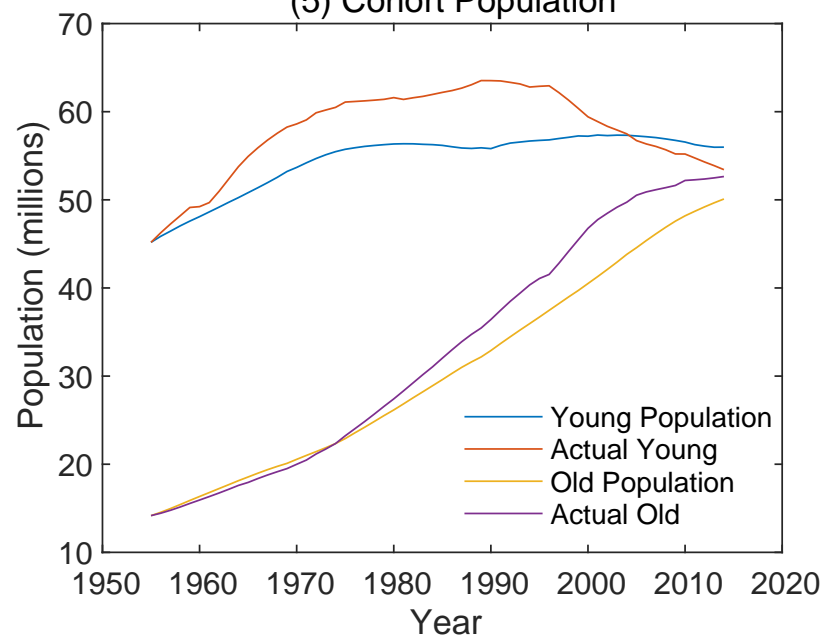

(2) Immigrants

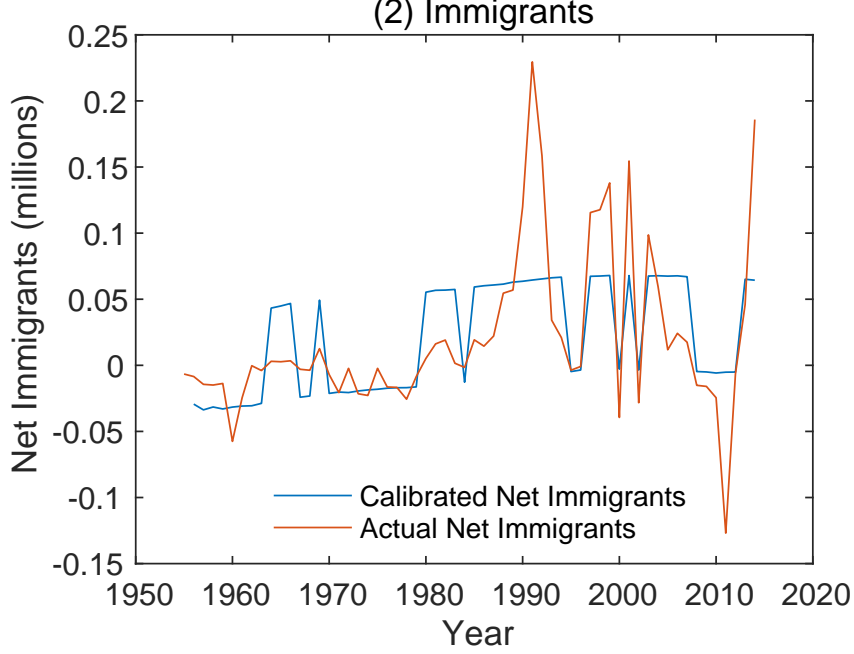

(4) Market Size

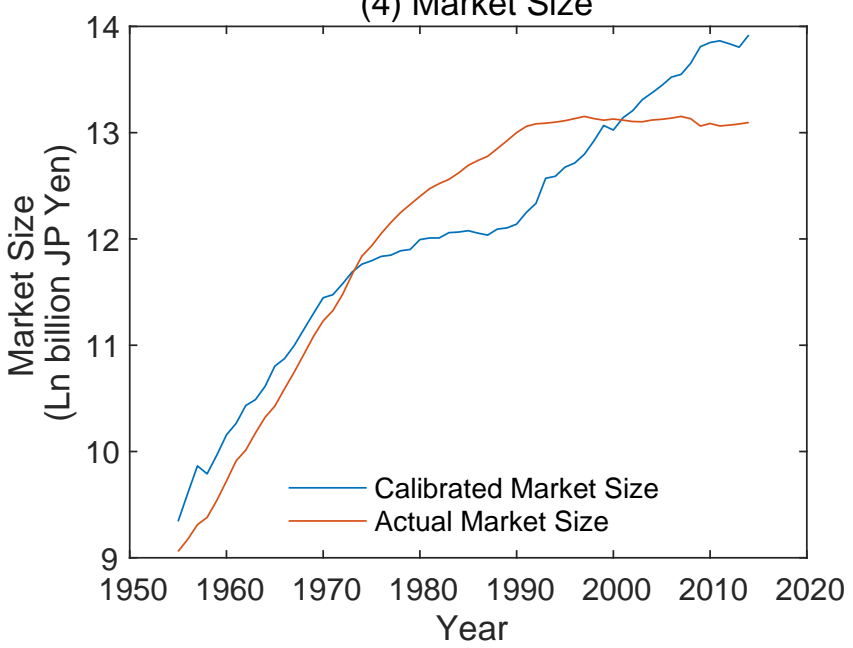

(6) per capita GDP

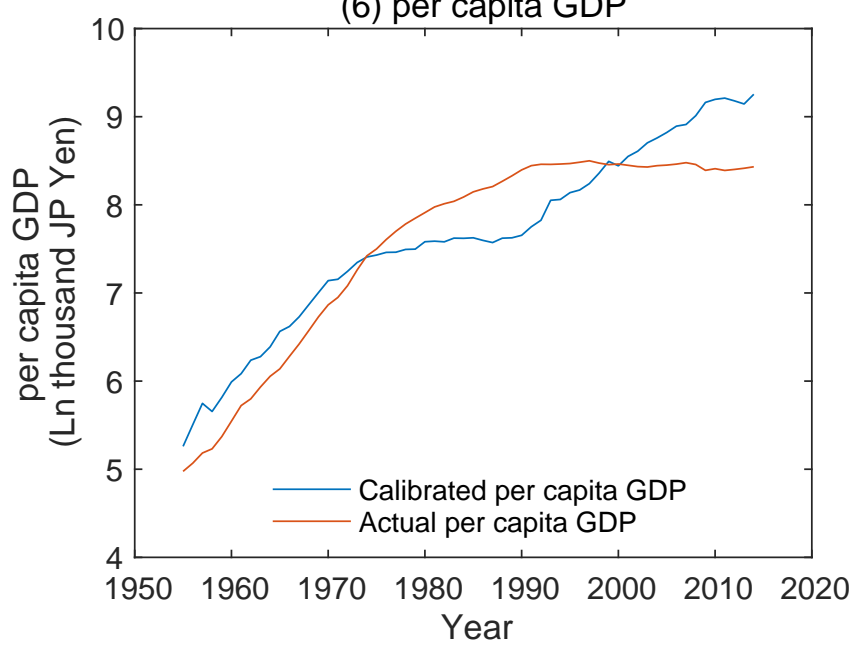

Figure 4-a: Calibration results (Japan) (upper-left: (1) Number of Birth, upper-right: (2) Immigrants, middle-left: (3) Total Population, middle-right: (4) Market Size, bottom-left: (5) Cohort population, bottom-right: (6) per capita GDP) 


\section{Calibration results (the U.S.)}
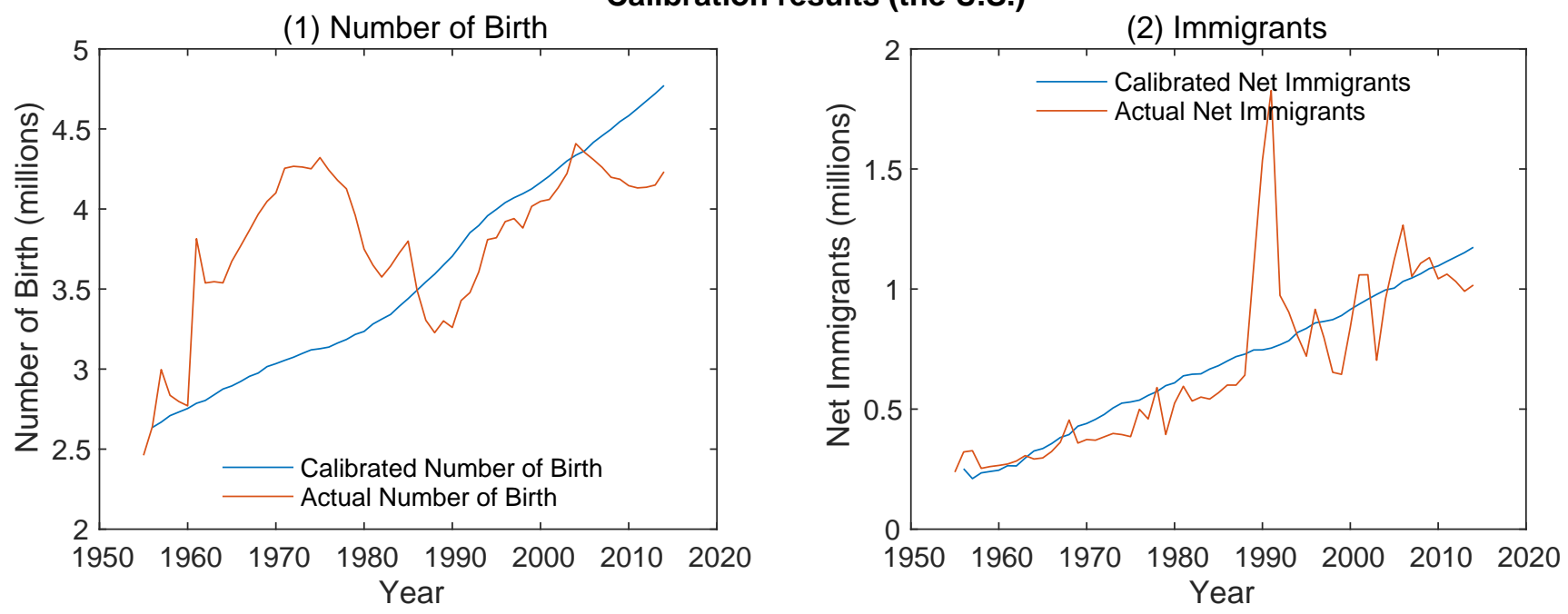

(3) Total Population

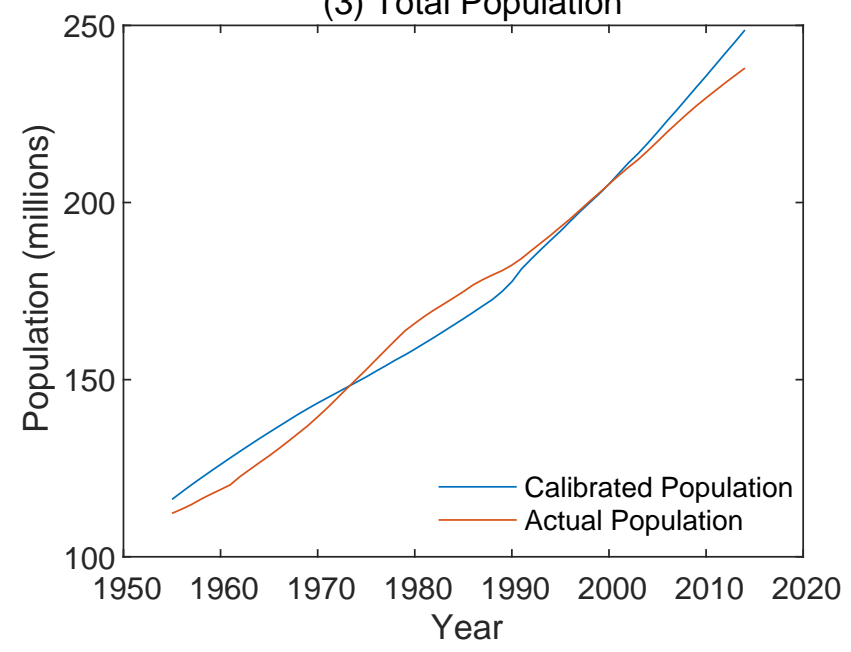

(5) Cohort Population

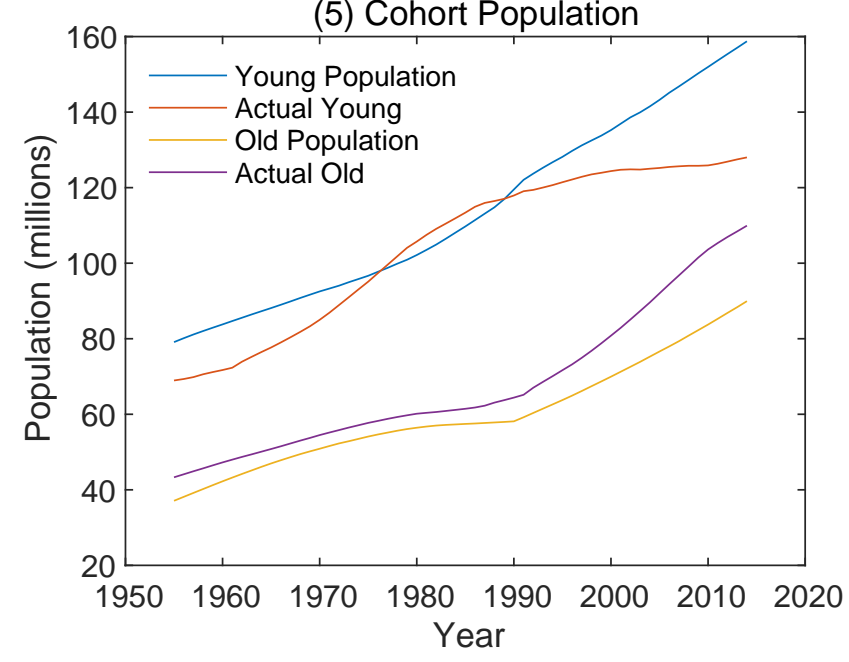

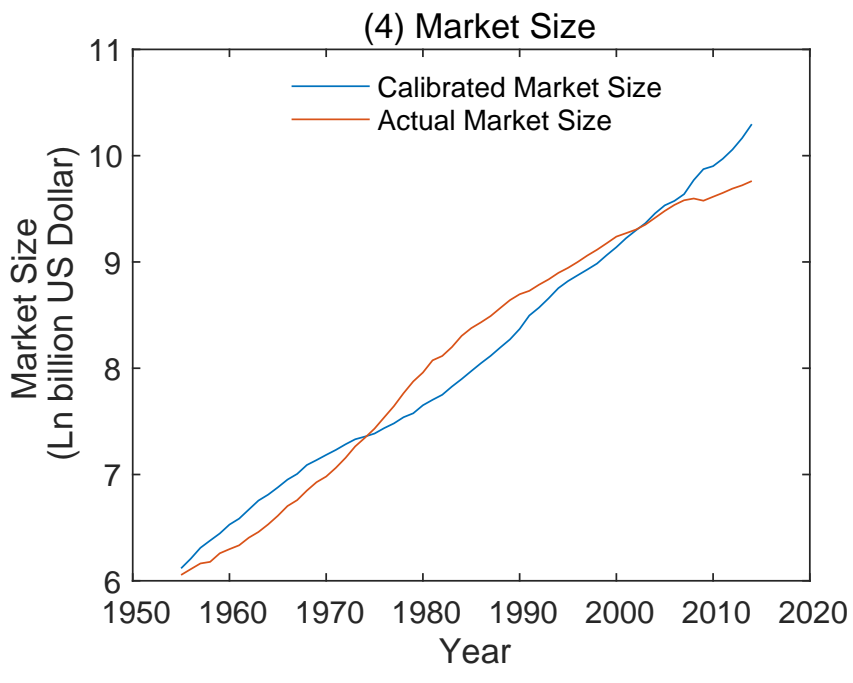

(6) per capita GDP

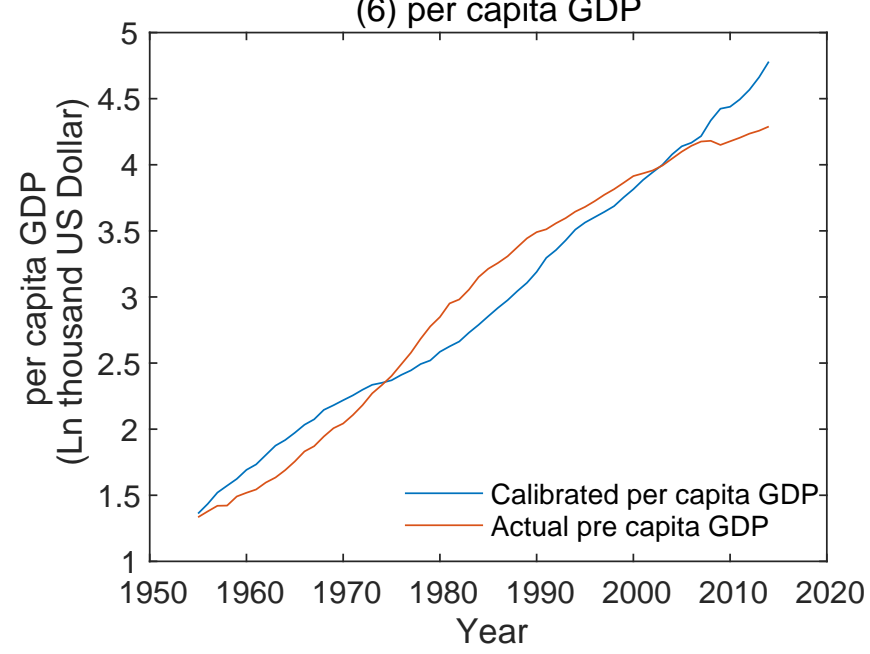

Figure 4-b: Calibration results (the U.S.) (upper-left: (1) Number of Birth, upper-right: (2) Immigrants, middle-left: (3) Total Population, middle-right: (4) Market Size, bottom-left: (5) Cohort population, bottom-right: (6) per capita GDP) 
(1) Number of Birth

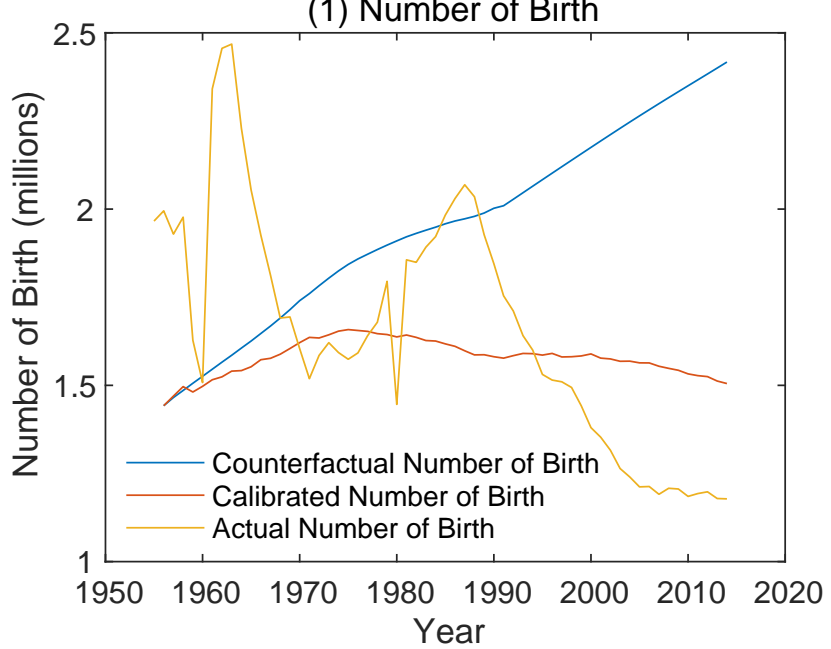

(3) Total Population

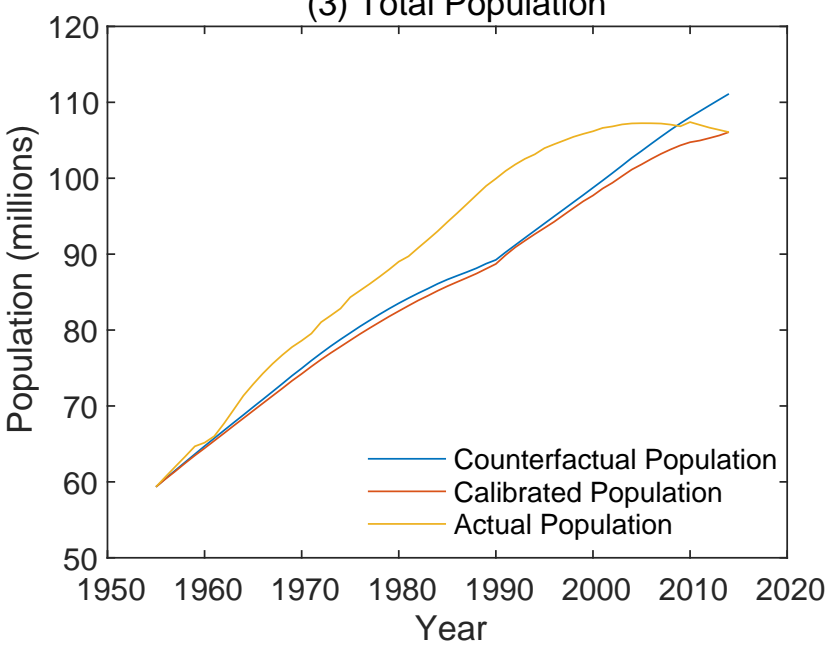

(5) Cohort Population

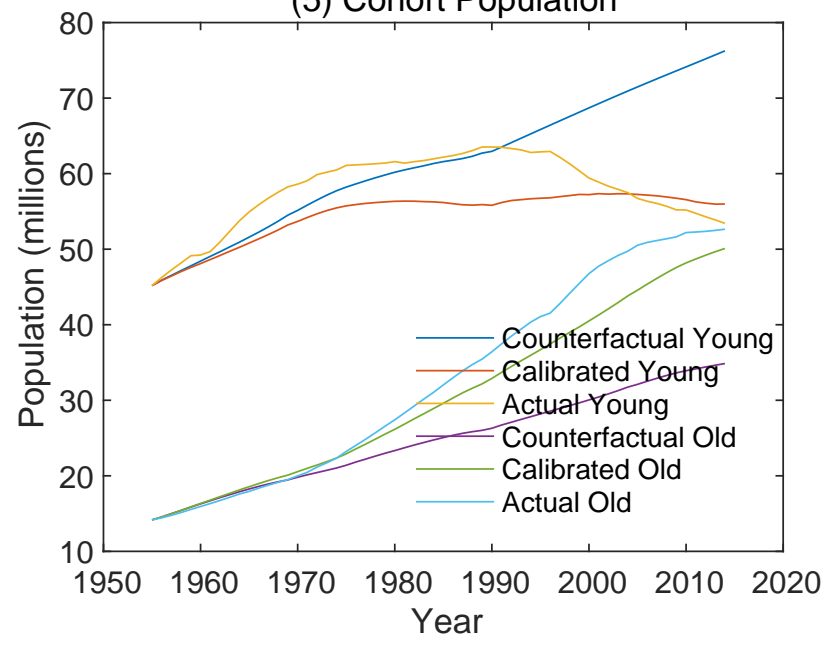

sis: low survival rate (Japan)

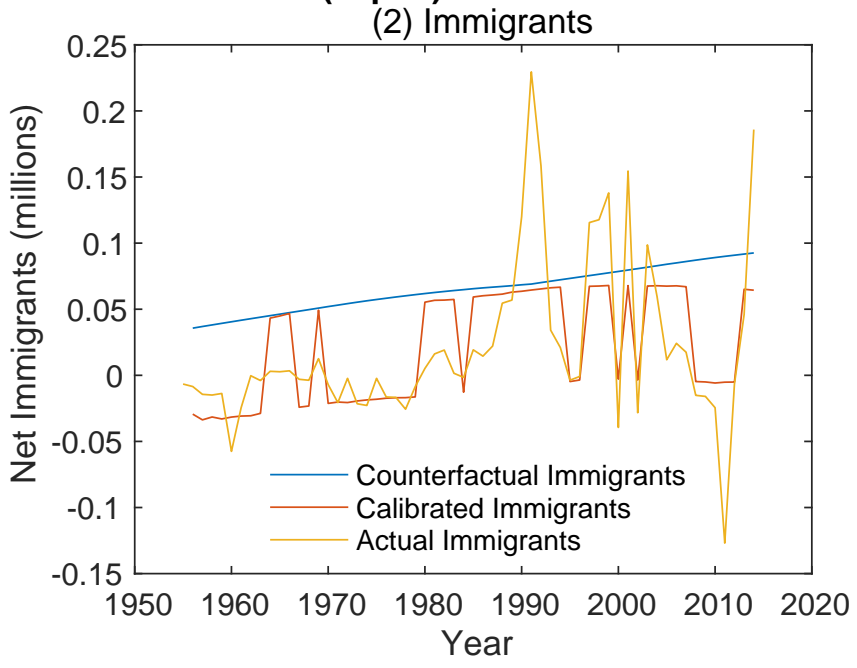

(4) Market Size

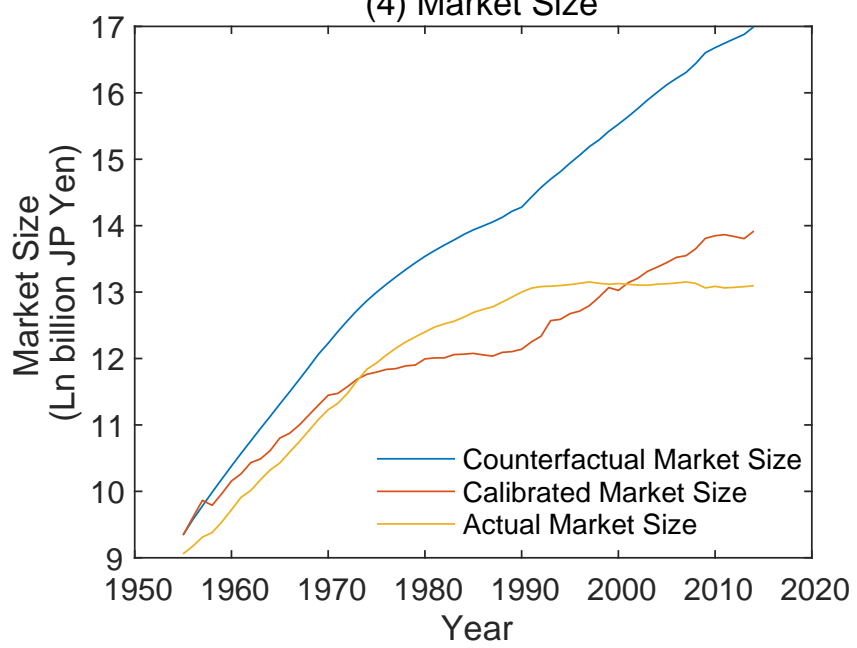

(6) per capita GDP

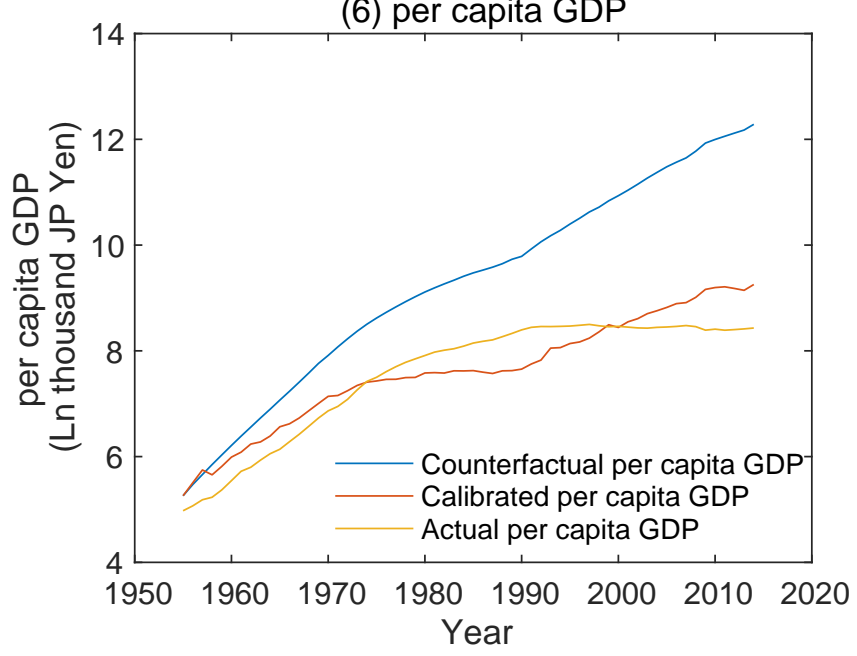

Figure 5-a: Counterfactual analysis: low survival rate (Japan) (upper-left: (1) Number of Birth, upper-right: (2) Immigrants, middle-left: (3) Total Population, middle-right: (4) Market Size, bottom-left: (5) Cohort population, bottom-right: (6) per capita GDP) 
Counterfactual analysis: low survival rate (the U.S.)

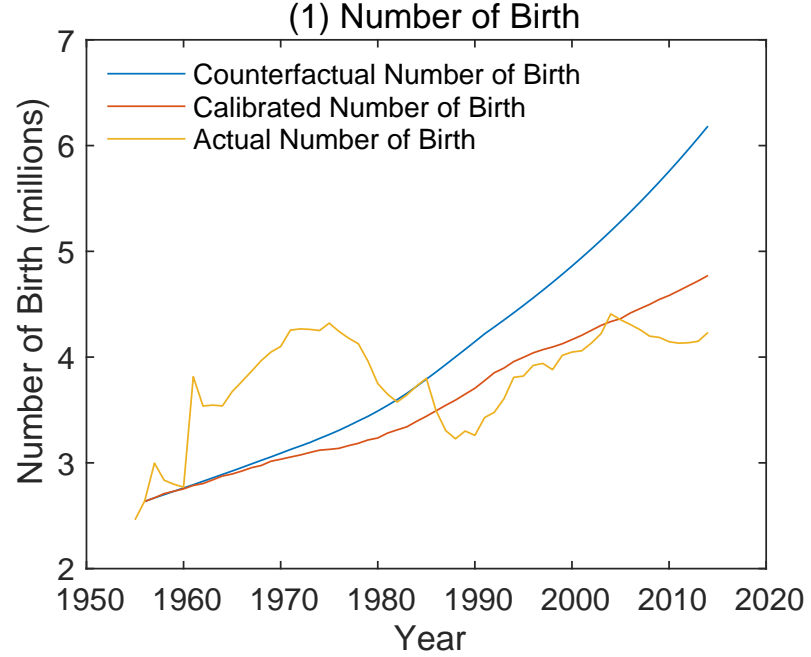

(2) Immigrants

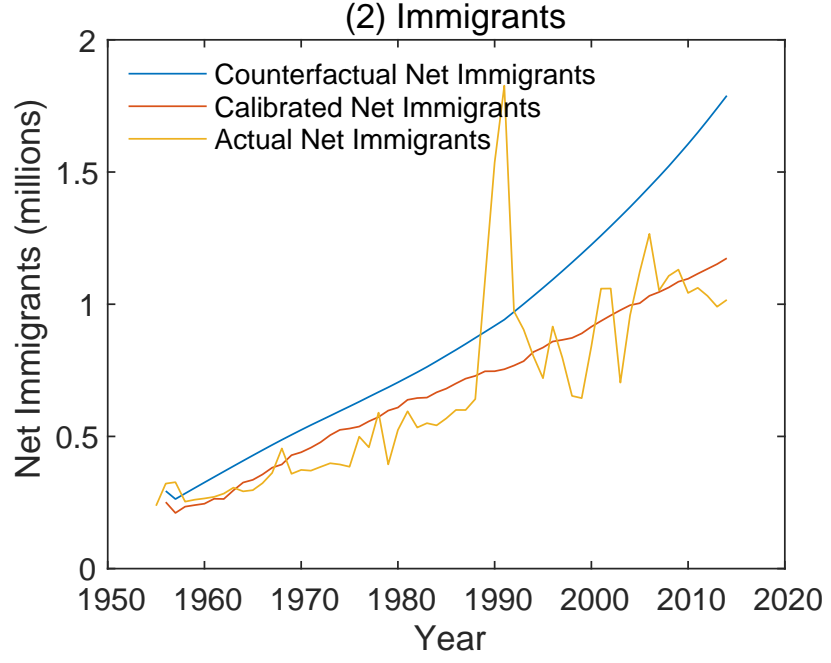

(3) Total Population

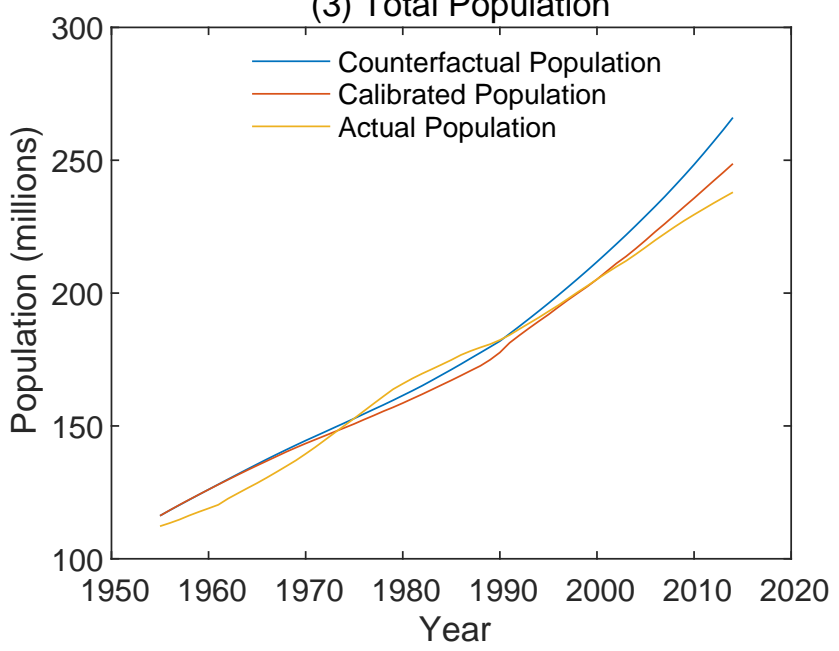

(4) Market Size

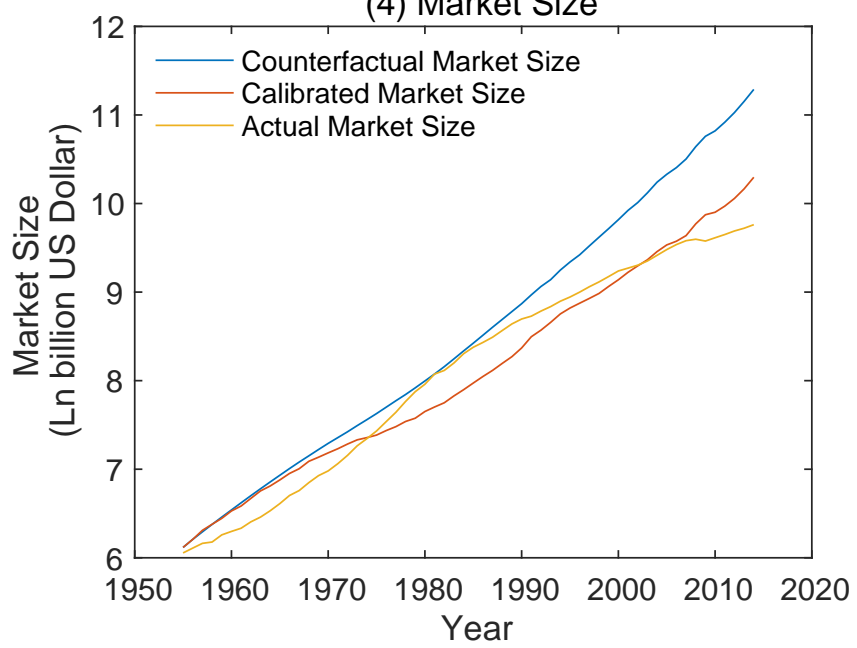

(5) Cohort Population
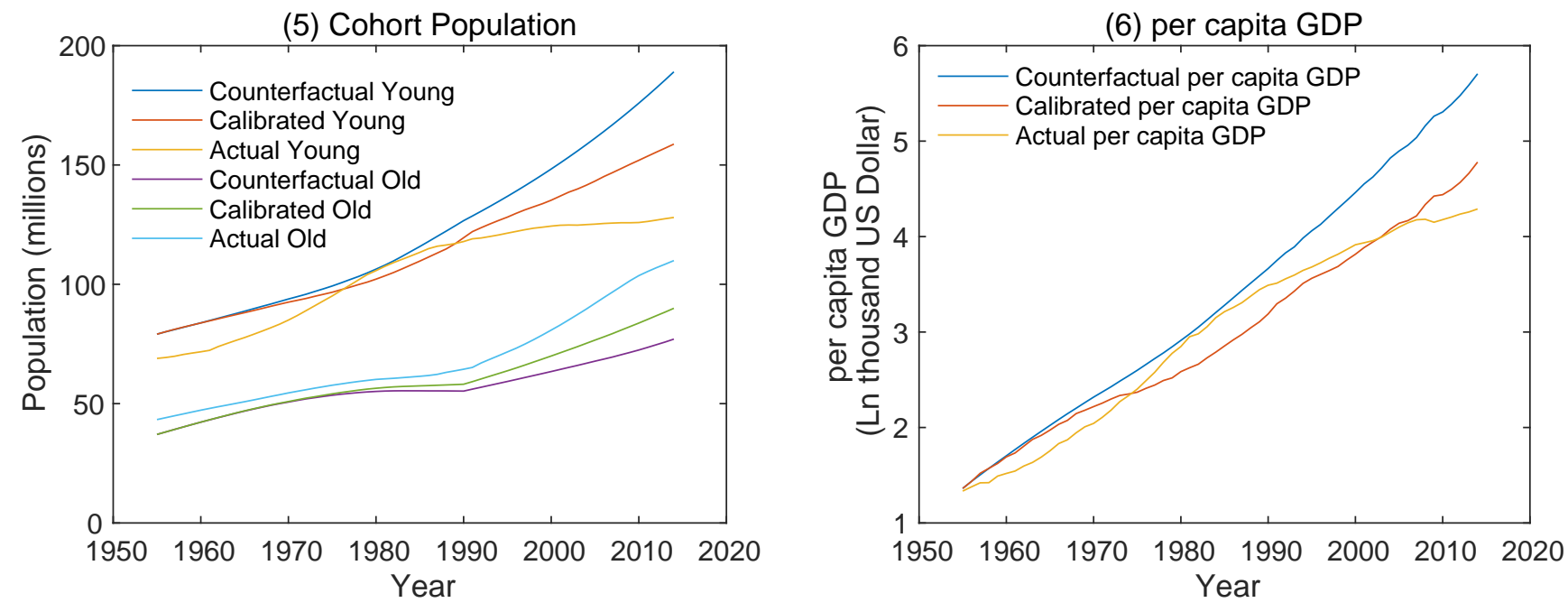

Figure 5-b: Counterfactual analysis: low survival rate (the U.S.)

(upper-left: (1) Number of Birth, upper-right: (2) Immigrants, middle-left: (3) Total Population,

middle-right: (4) Market Size, bottom-left: (5) Cohort population, bottom-right: (6) per capita GDP) 
Counterfactual analysis: high survival rate (Japan)
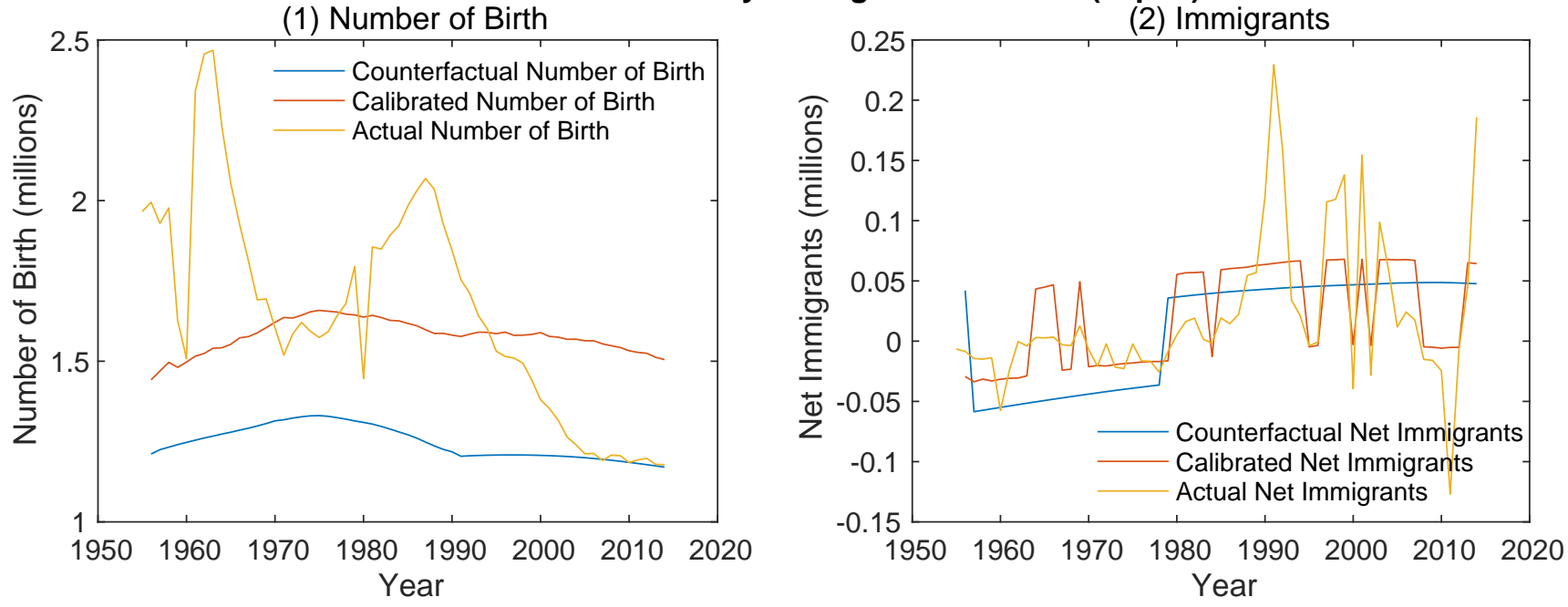

(3) Total Population
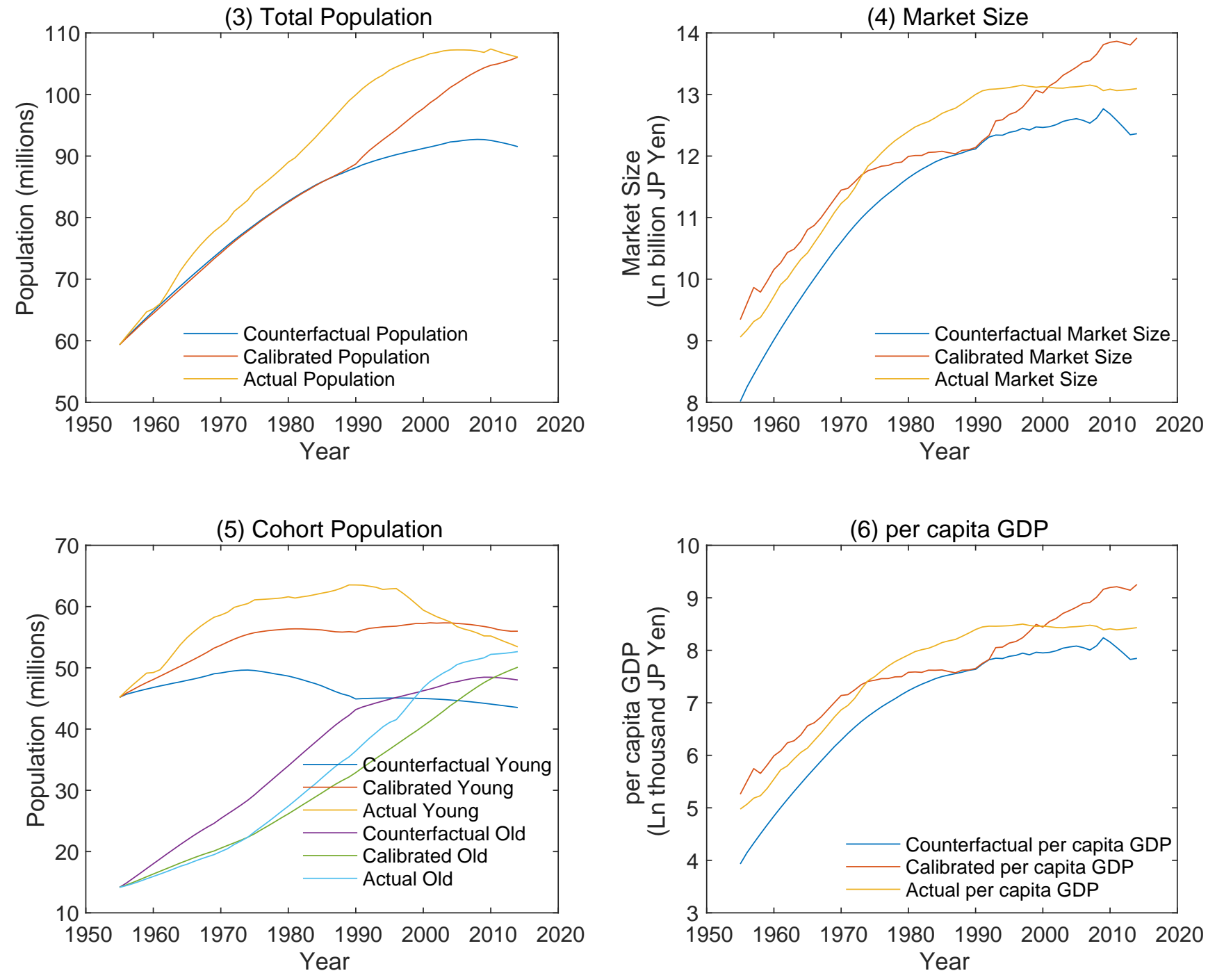

Figure 6-a: Counterfactual analysis: high survival rate (Japan)

(upper-left: (1) Number of Birth, upper-right: (2) Immigrants, middle-left: (3) Total Population,

middle-right: (4) Market Size, bottom-left: (5) Cohort population, bottom-right: (6) per capita GDP) 

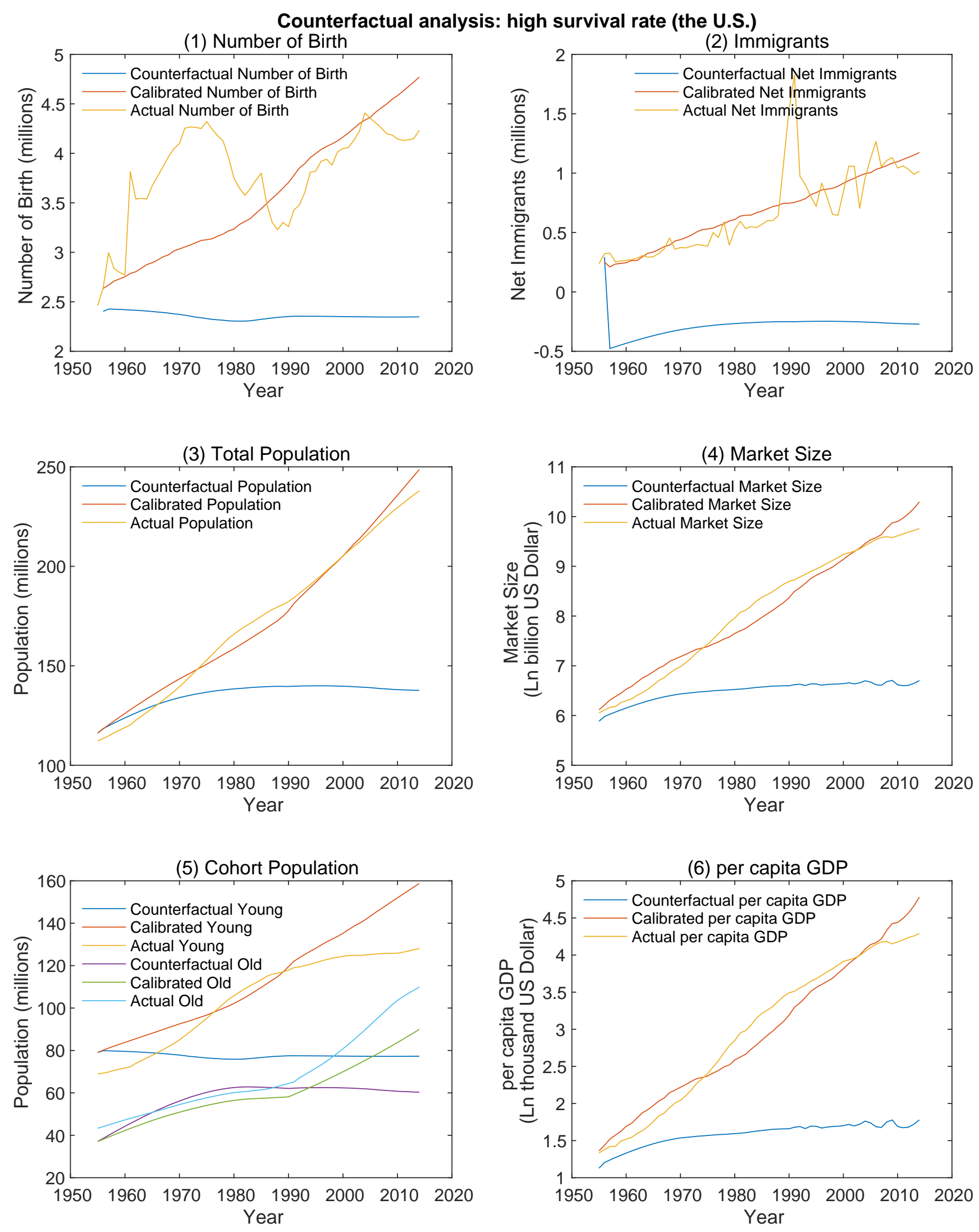

Figure 6-b: Counterfactual analysis: high survival rate (the U.S.)

(upper-left: (1) Number of Birth, upper-right: (2) Immigrants, middle-left: (3) Total Population,

middle-right: (4) Market Size, bottom-left: (5) Cohort population, bottom-right: (6) per capita GDP) 
Counterfactual analysis: openness towards immigration (Japan)

(1) Number of Birth

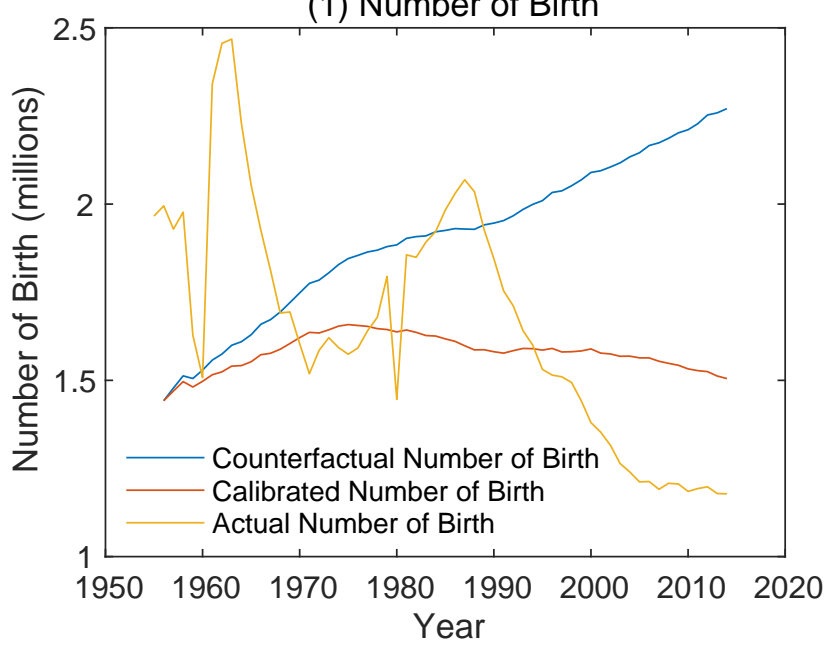

(3) Total Population

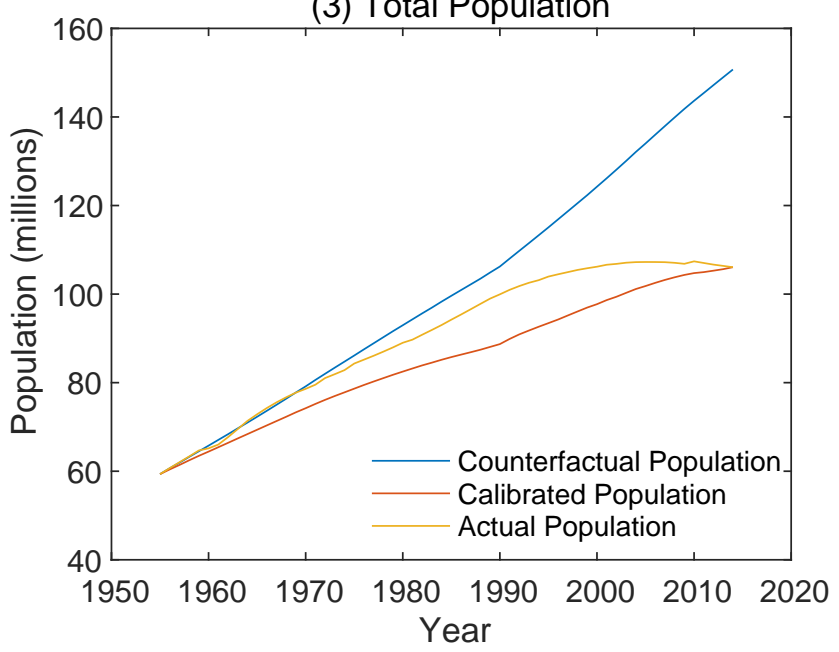

(5) Cohort Population

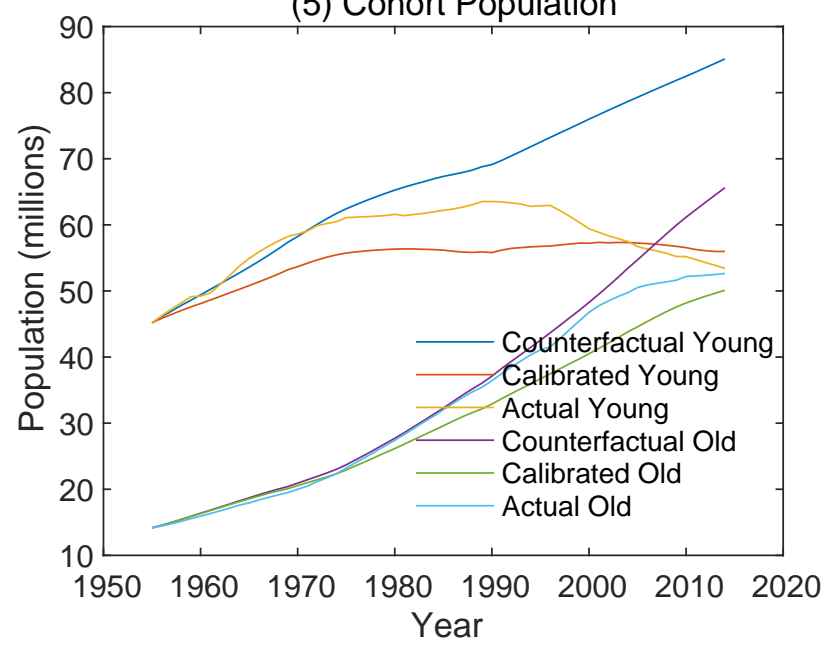

(2) Immigrants

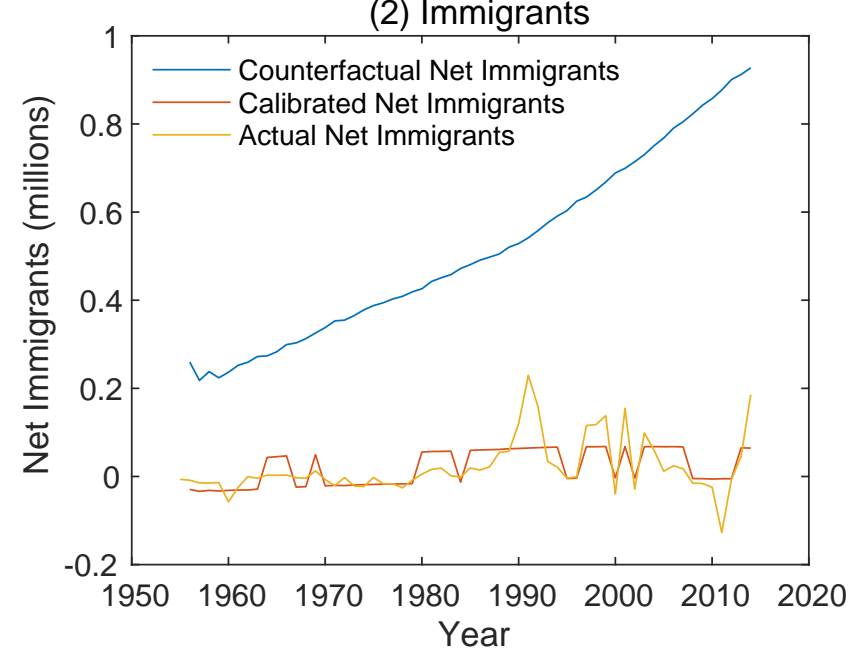

(4) Market Size

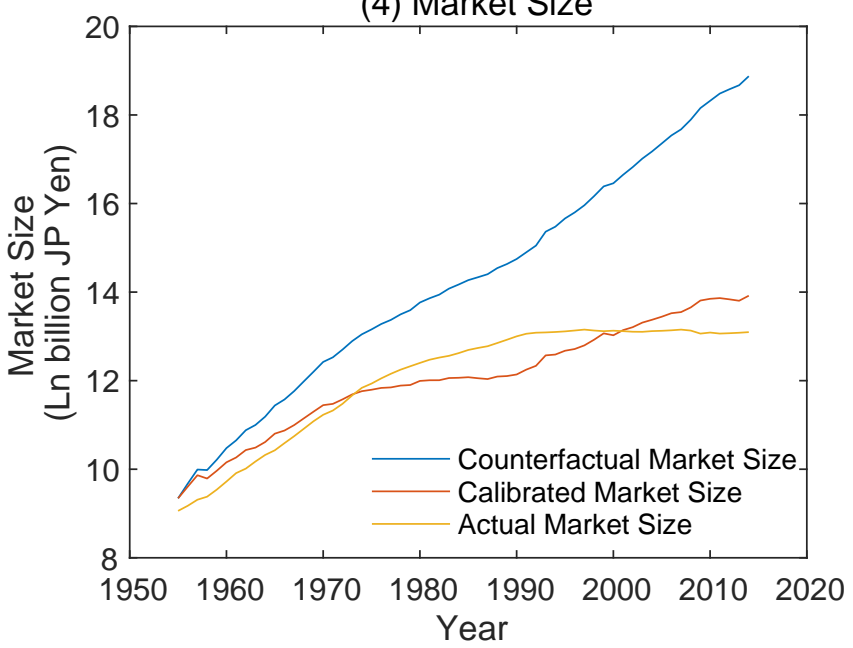

(6) per capita GDP

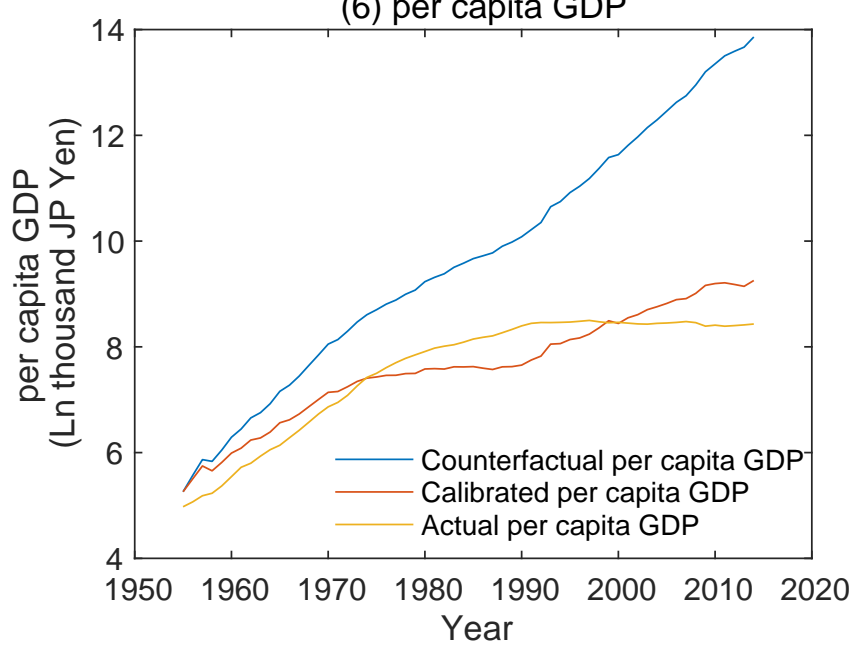

Figure 7-a: Counterfactual analysis: openness towards immigration (Japan) (upper-left: (1) Number of Birth, upper-right: (2) Immigrants, middle-left: (3) Total Population, middle-right: (4) Market Size, bottom-left: (5) Cohort population, bottom-right: (6) per capita GDP) 
Counterfactual analysis: openness towards immigration (the U.S.)

(1) Number of Birth

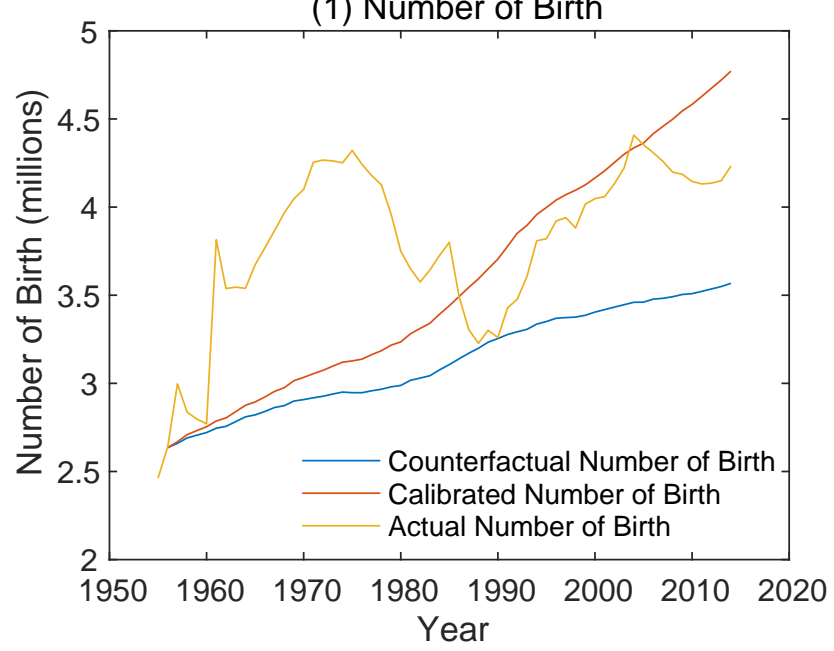

(3) Total Population

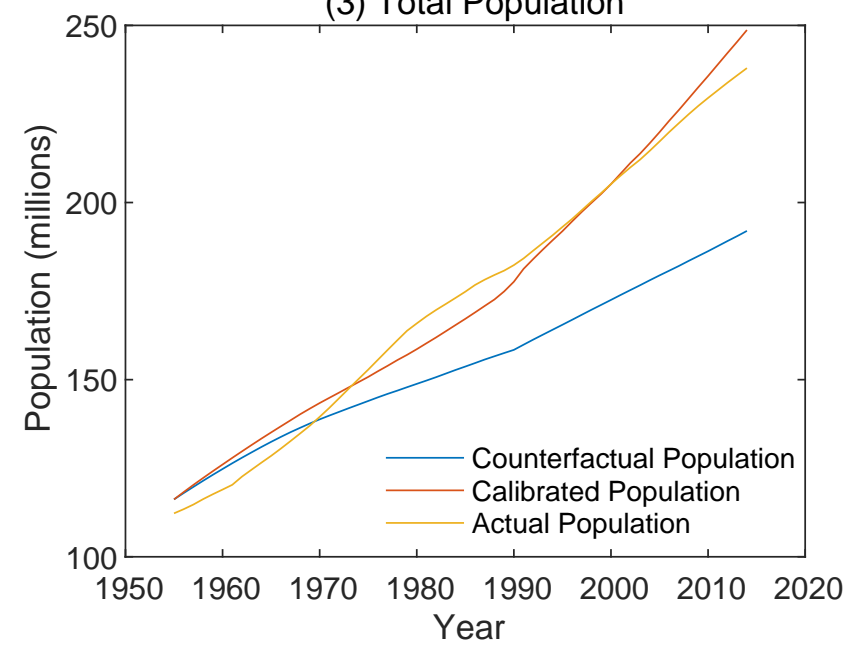

(5) Cohort Population

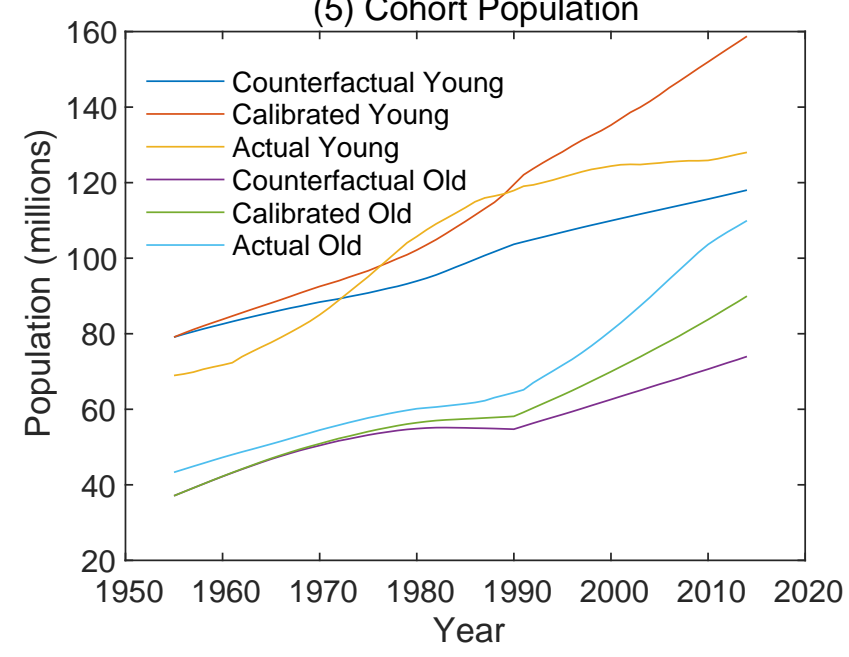

(2) Immigrants

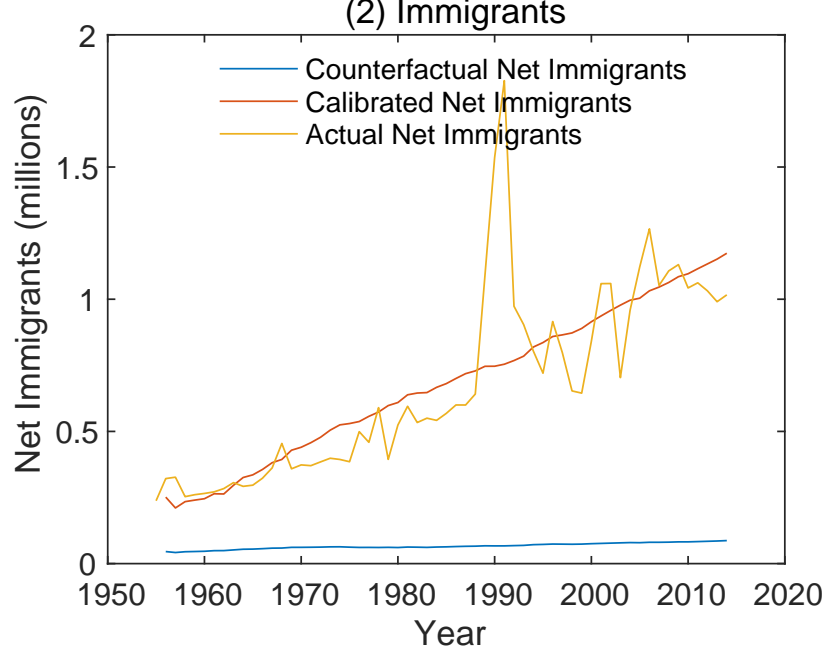

(4) Market Size

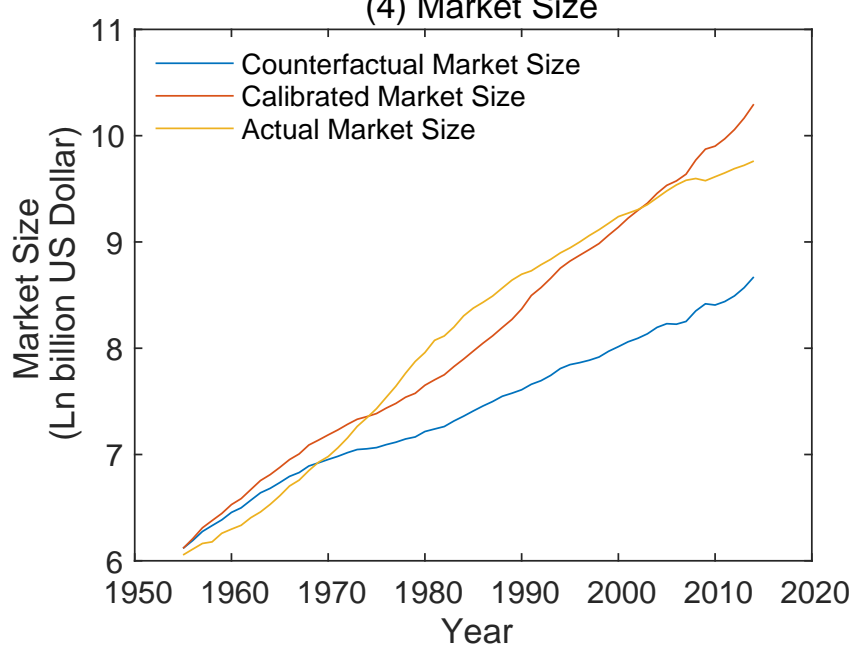

(6) per capita GDP

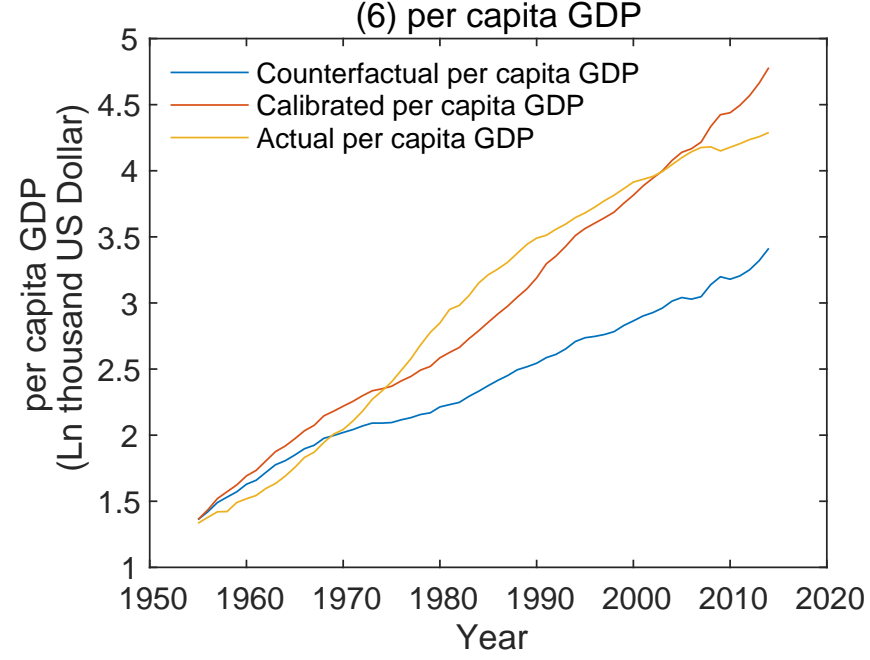

Figure 7-b: Counterfactual analysis: openness towards immigration (the U.S.)

(upper-left: (1) Number of Birth, upper-right: (2) Immigrants, middle-left: (3) Total Population,

middle-right: (4) Market Size, bottom-left: (5) Cohort population, bottom-right: (6) per capita GDP) 
Robustness check: case of $b=0.4$ (Japan)
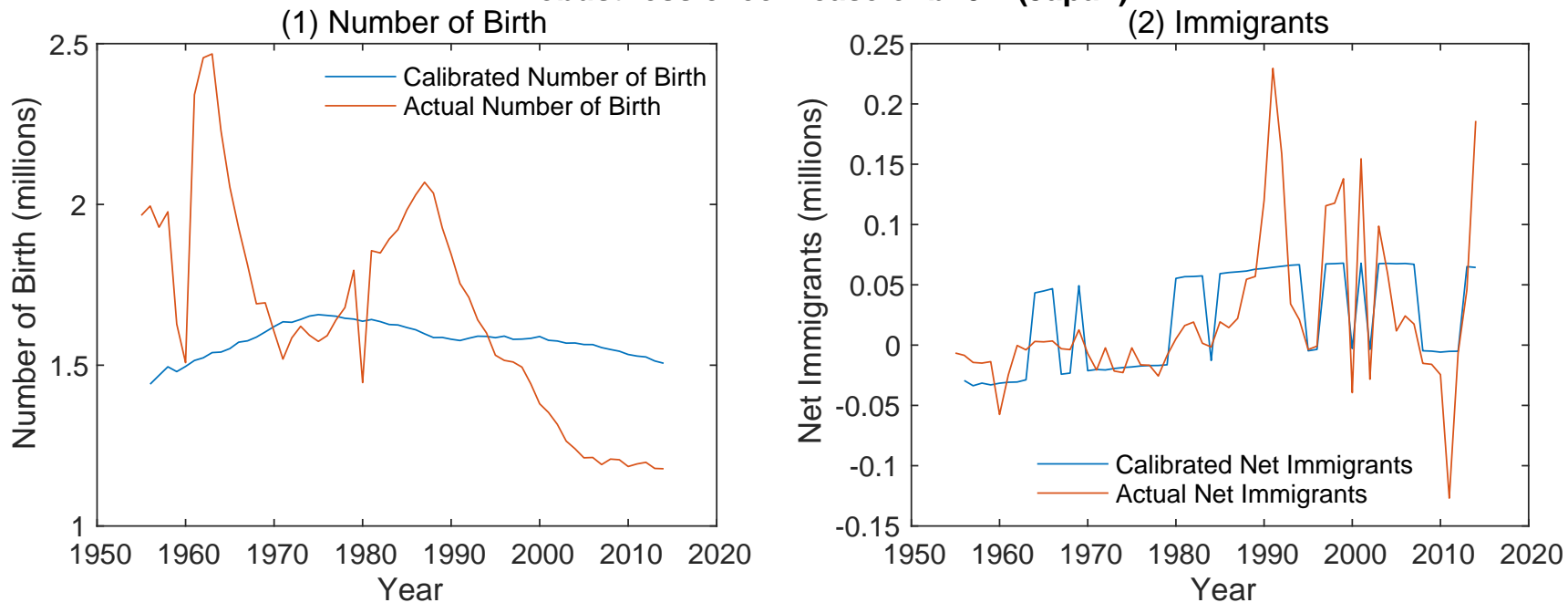

(3) Total Population
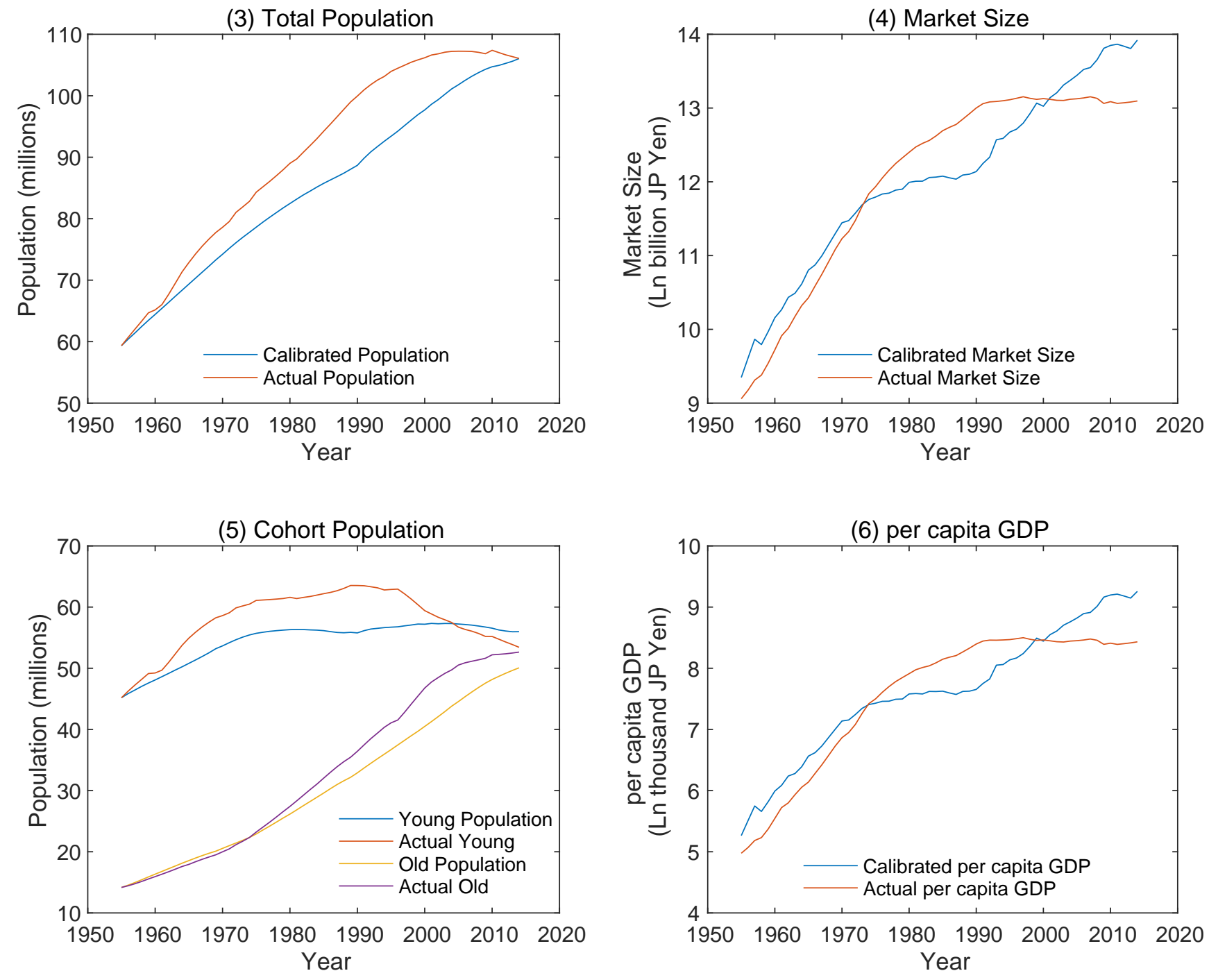

Figure 8-a: Robustness check: case of $b=0.4$ (Japan) (upper-left: (1) Number of Birth, upper-right: (2) Immigrants, middle-left: (3) Total Population, middle-right: (4) Market Size, bottom-left: (5) Cohort population, bottom-right: (6) per capita GDP) 
Robustness check: case of $b=0.4$ (the U.S.)
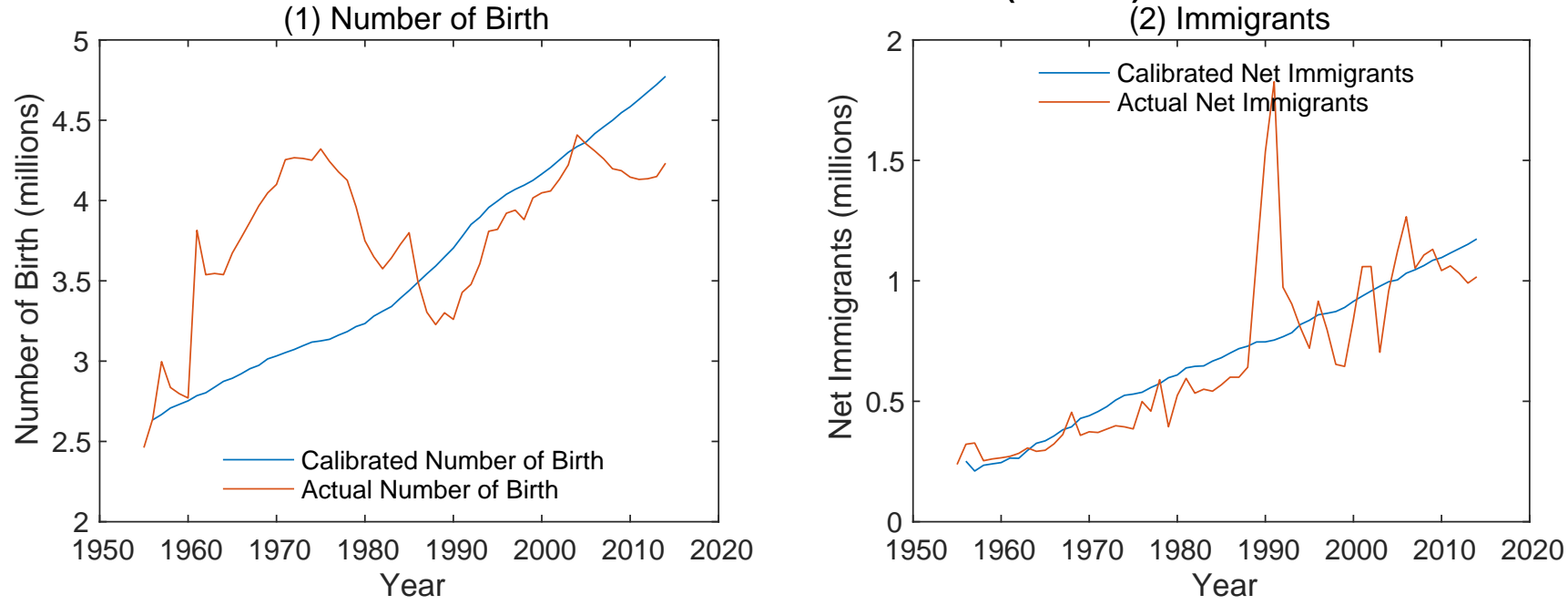

(3) Total Population
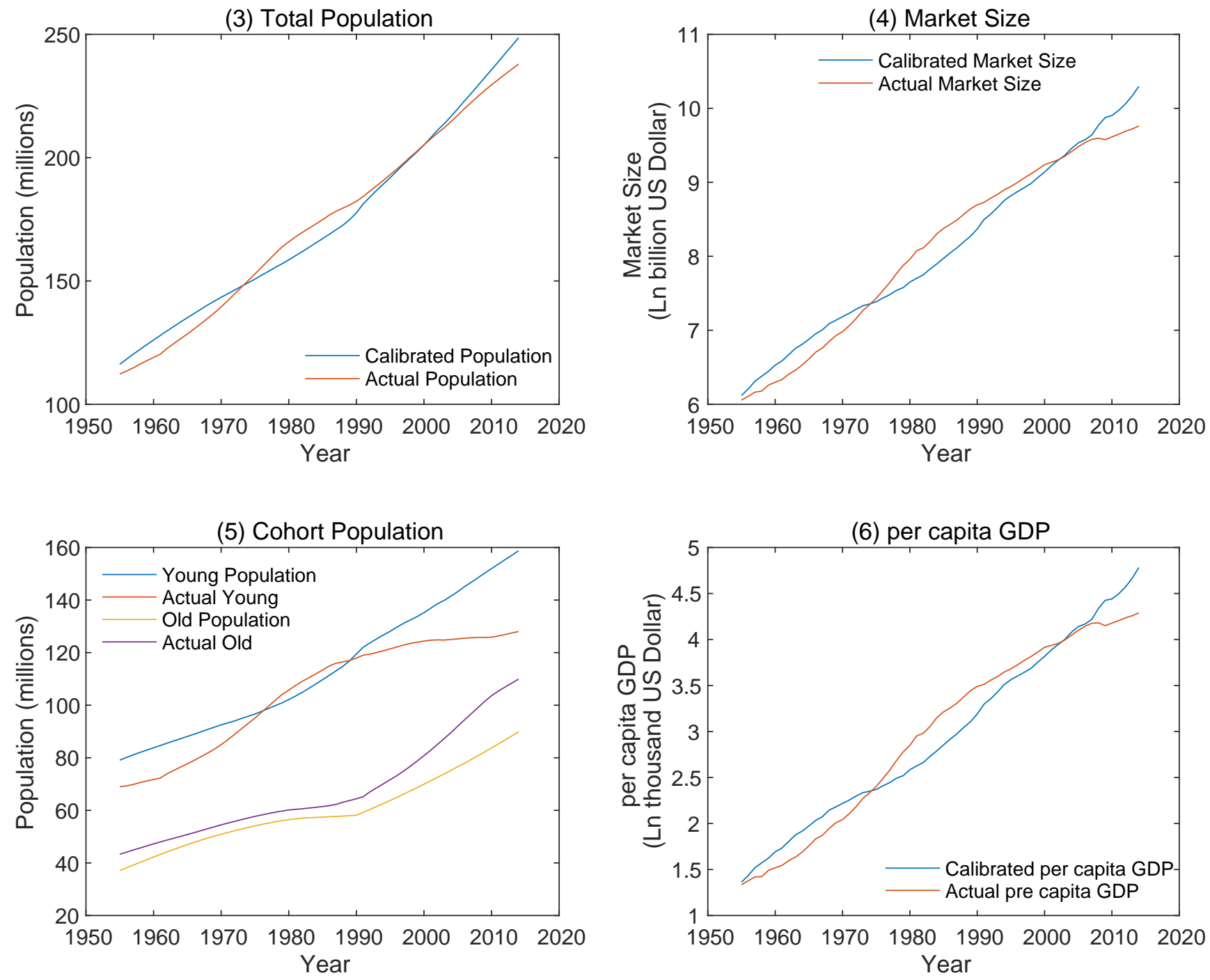

Figure 8-b: Robustness check: case of $b=0.4$ (the U.S.)

(upper-left: (1) Number of Birth, upper-right: (2) Immigrants, middle-left: (3) Total Population,

middle-right: (4) Market Size, bottom-left: (5) Cohort population, bottom-right: (6) per capita GDP) 
Robustness check: changing parameter $\beta$ (Japan)
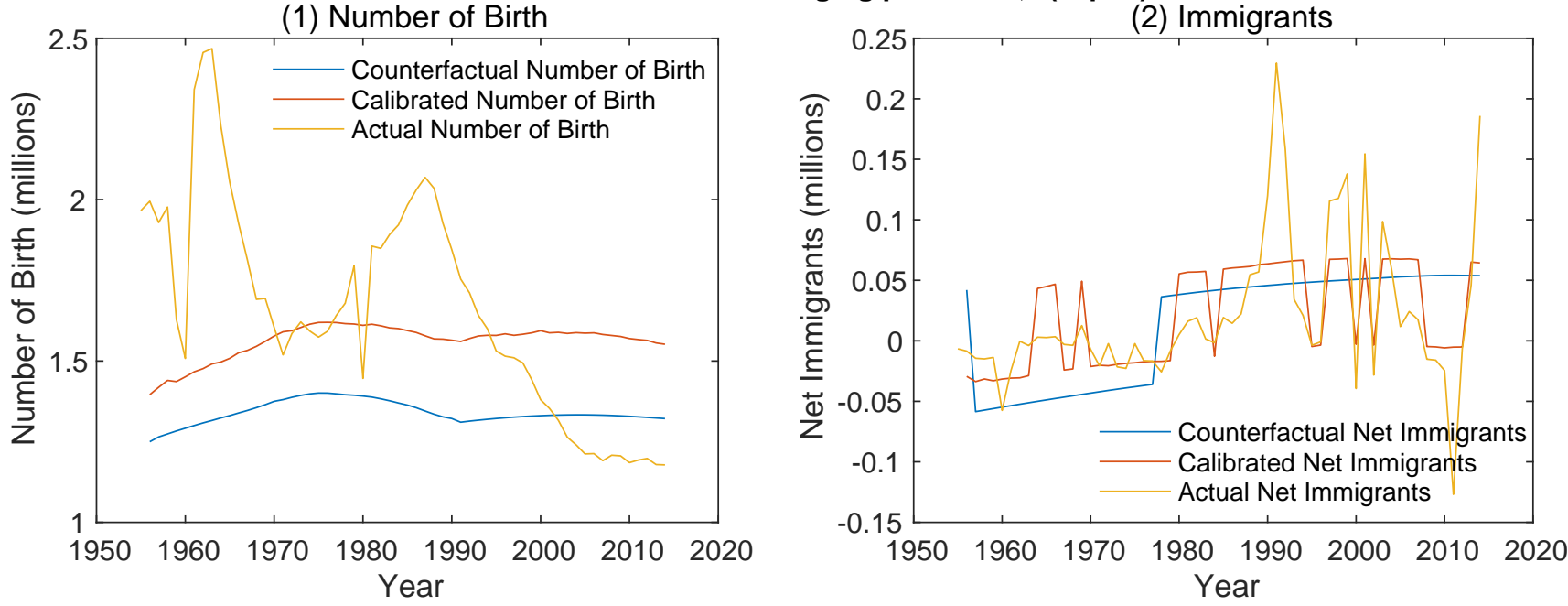

(3) Total Population

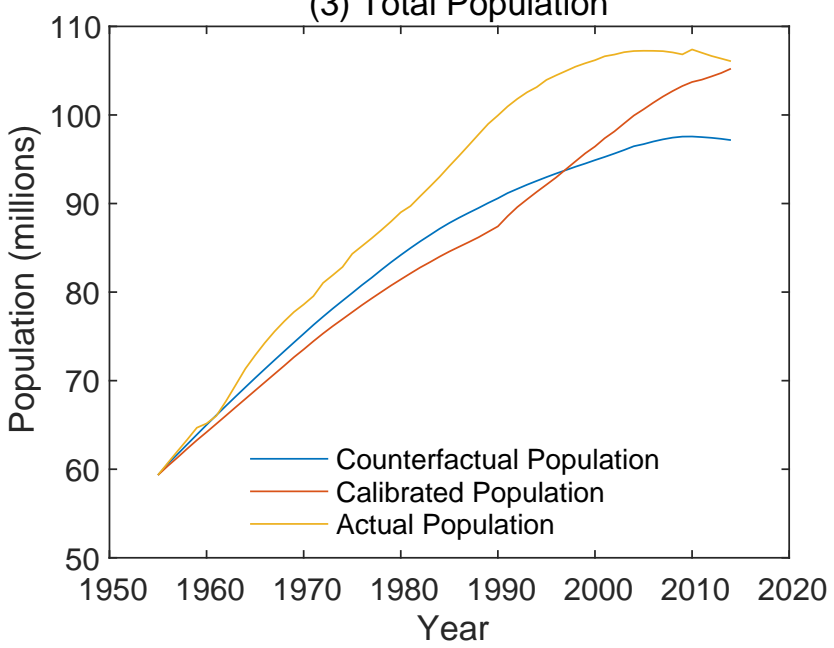

(5) Cohort Population

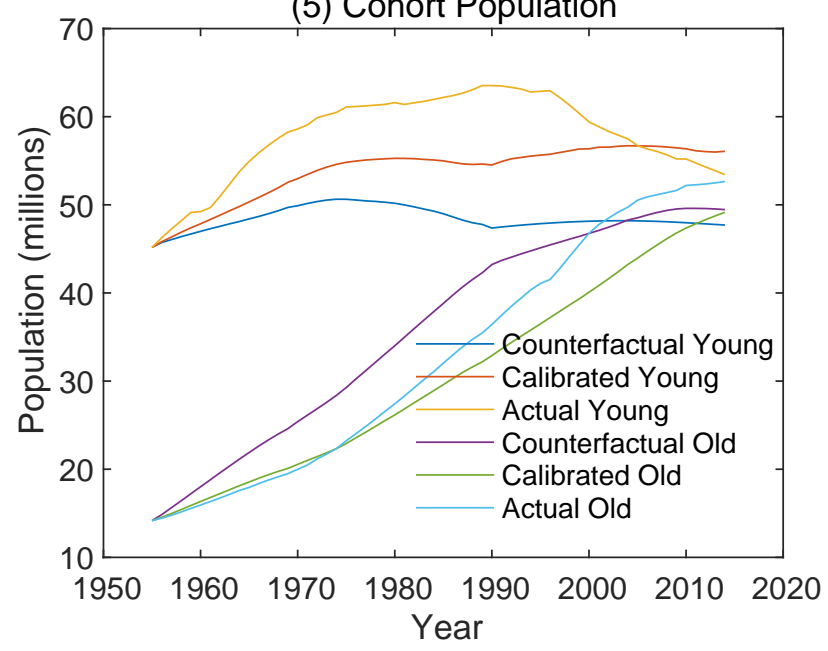

(4) Market Size

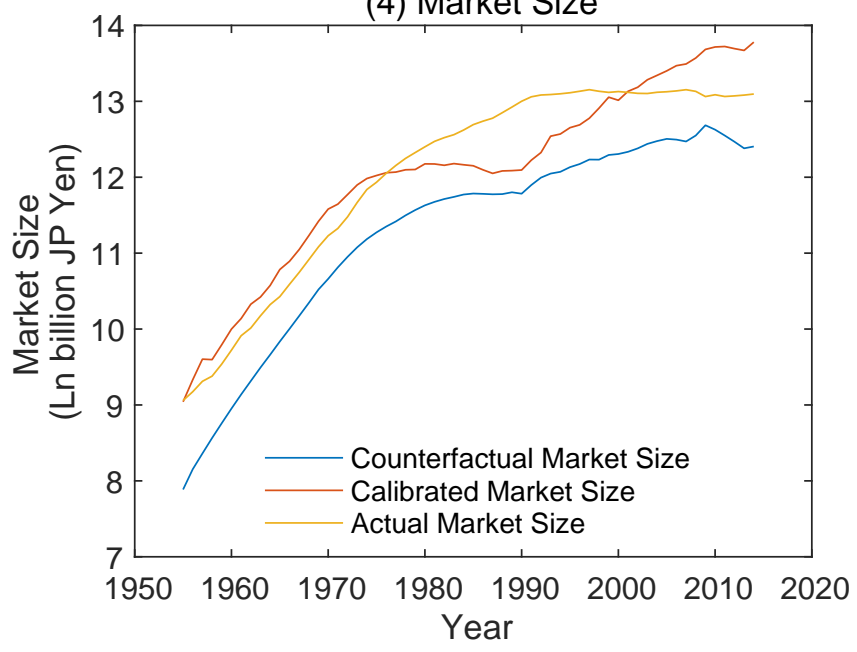

(6) per capita GDP

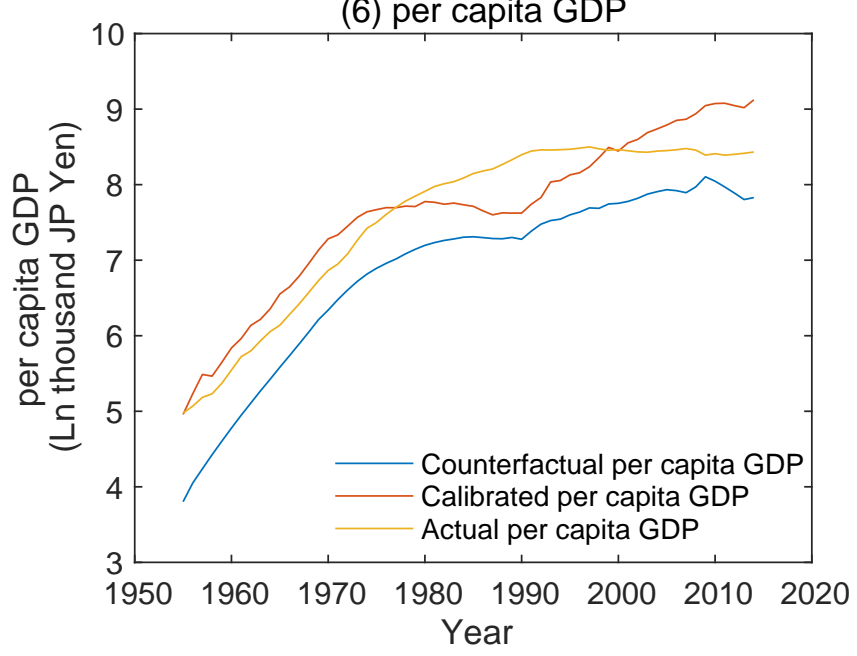

Figure 9-a: Robustness check: changing parameter $\beta$ (Japan)

(upper-left: (1) Number of Birth, upper-right: (2) Immigrants, middle-left: (3) Total Population,

middle-right: (4) Market Size, bottom-left: (5) Cohort population, bottom-right: (6) per capita GDP) 
Robustness check: changing parameter $\beta$ (the U.S.)

(1) Number of Birth
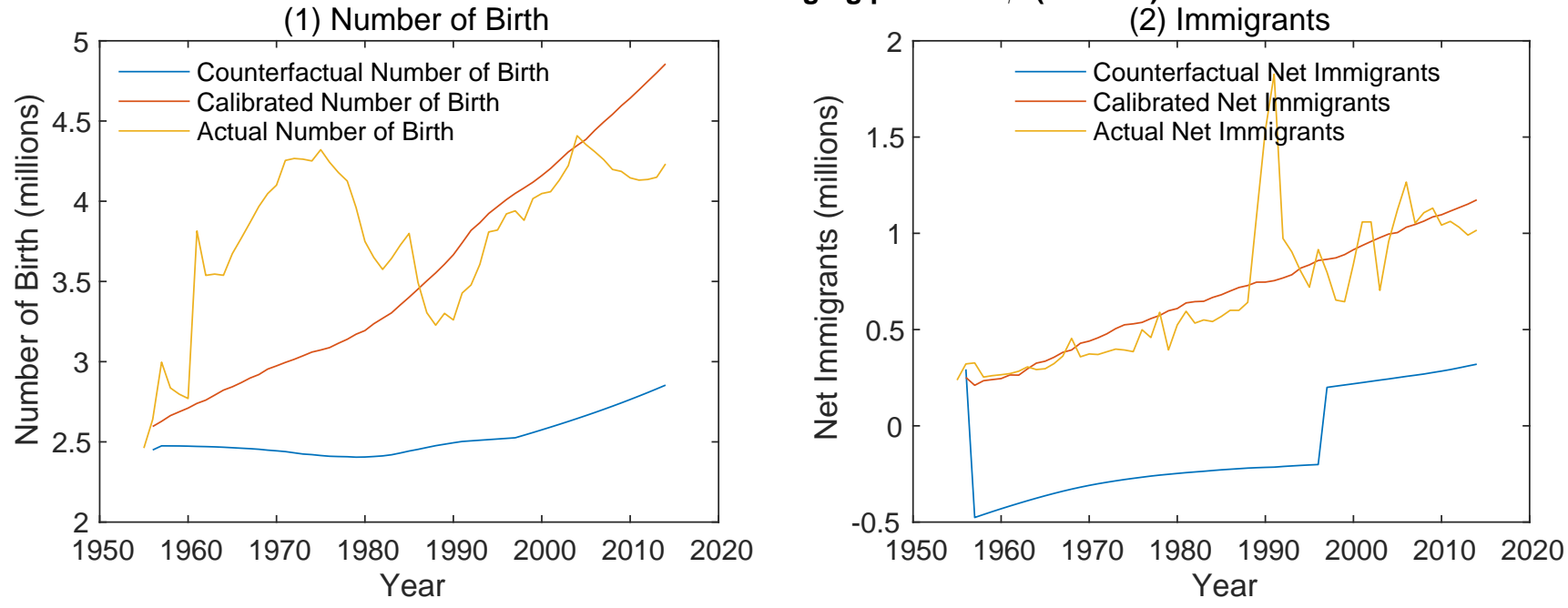

(3) Total Population
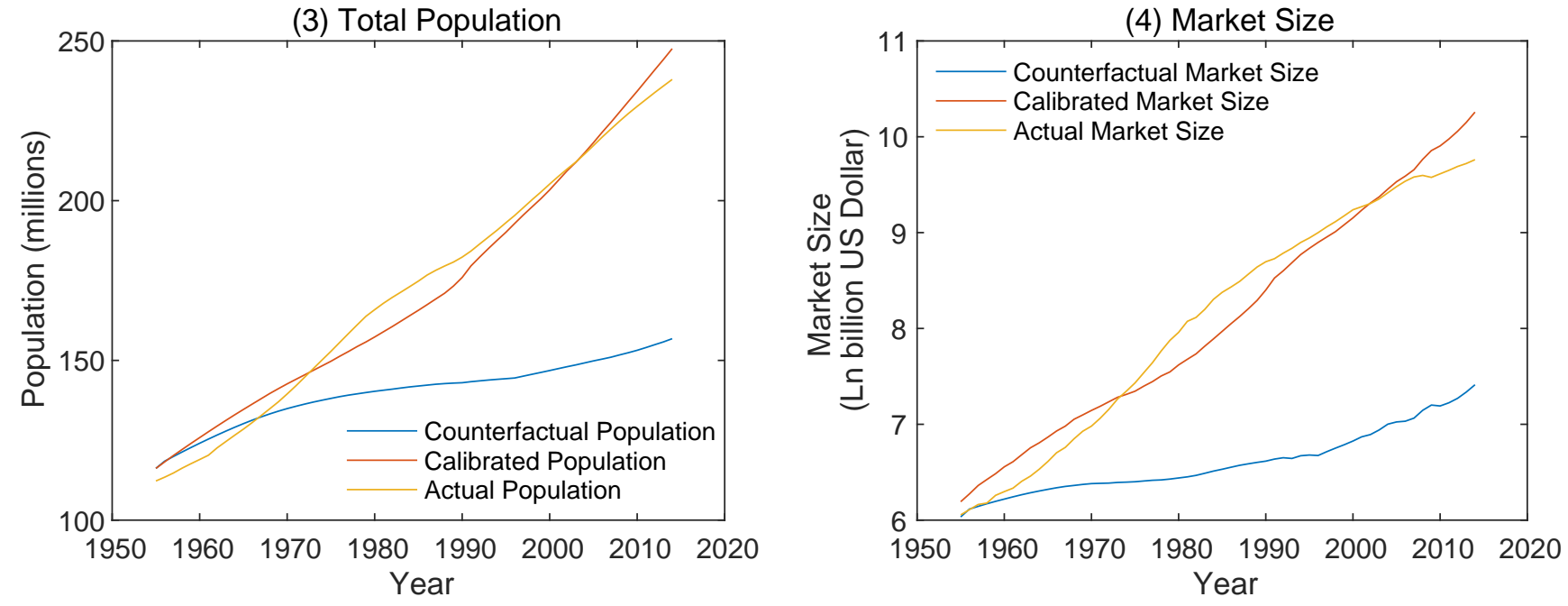

(5) Cohort Population
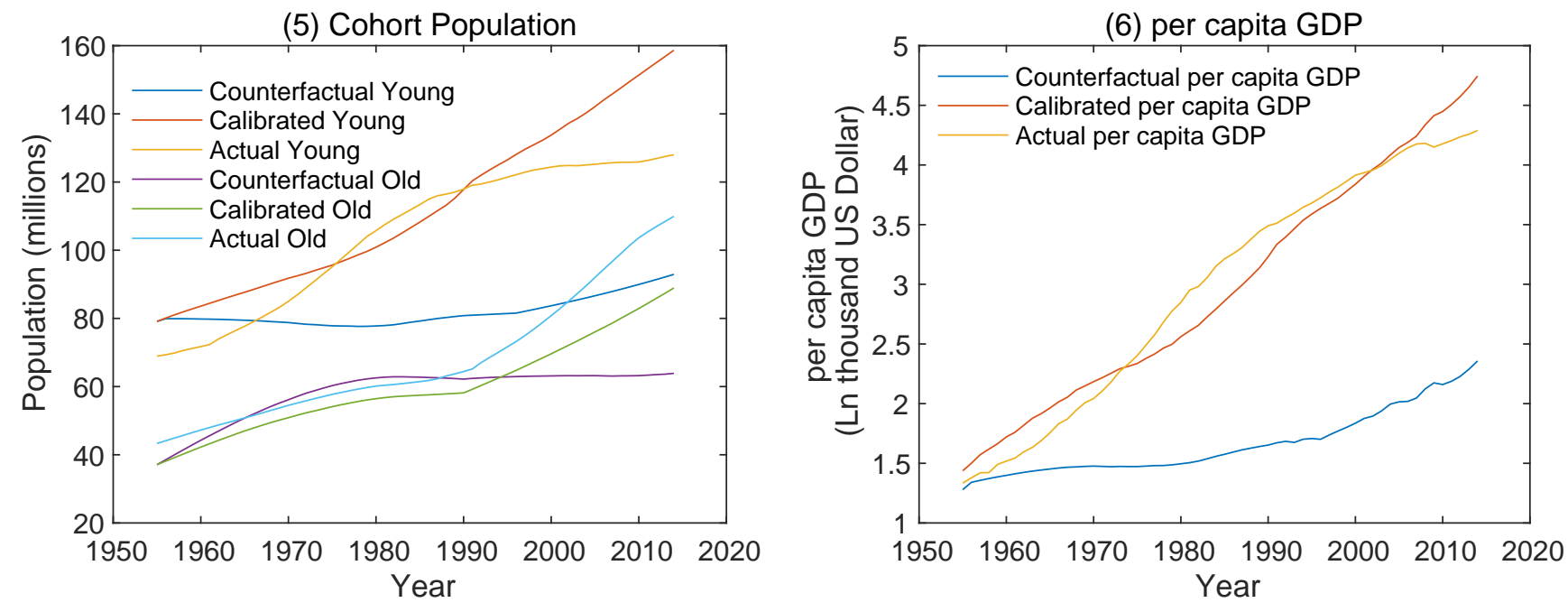

Figure 9-b: Robustness check: changing parameter $\beta$ (the U.S.)

(upper-left: (1) Number of Birth, upper-right: (2) Immigrants, middle-left: (3) Total Population,

middle-right: (4) Market Size, bottom-left: (5) Cohort population, bottom-right: (6) per capita GDP) 